\title{
A Fast Converging Hybrid MPPT Algorithm Based on ABC and P\&O Techniques for a Partially Shaded PV System
}

\author{
Carlos Restrepo $^{1,+} \oplus$, Nicolas Yanẽz-Monsalvez ${ }^{1,+} \oplus$, Catalina González-Castaño ${ }^{2, *,+} \oplus$, Samir Kouro ${ }^{3,+} \oplus$ \\ and Jose Rodriguez ${ }^{2,+} \mathbb{D}$ \\ 1 Department of Electromechanics and Energy Conversion, Universidad de Talca, Curicó 3340000, Chile; \\ crestrepo@utalca.cl (C.R.); nyanez16@alumnos.utalca.cl (N.Y.-M.) \\ 2 Department of Engineering Sciences, Universidad Andres Bello, Santiago 7500971, Chile; \\ jose.rodriguez@unab.cl \\ 3 Electronics Engineering Department, Universidad Técnica Federico Santa María, Valparaíso 2390123, Chile; \\ samir.kouro@usm.cl \\ * Correspondence: inv.cet@unab.cl \\ + These authors contributed equally to this work.
}

check for

updates

Citation: Restrepo, C.;

Yanẽz-Monsalvez, N.;

González-Castaño, C.; Kouro, S.;

Rodriguez, J. A Fast Converging

Hybrid MPPT Algorithm Based on

$\mathrm{ABC}$ and $\mathrm{P \& O}$ Techniques for a

Partially Shaded PV System.

Mathematics 2021, 9, 2228. https://

doi.org/10.3390/math9182228

Academic Editor: Pedro Beirão

Received: 11 August 2021

Accepted: 4 September 2021

Published: 10 September 2021

Publisher's Note: MDPI stays neutral with regard to jurisdictional claims in published maps and institutional affiliations.

Copyright: (C) 2021 by the authors. Licensee MDPI, Basel, Switzerland. This article is an open access article distributed under the terms and conditions of the Creative Commons Attribution (CC BY) license (https:// creativecommons.org/licenses/by/ $4.0 /)$.

\begin{abstract}
Among all the conventional maximum power point tracking (MPPT) techniques for a photovoltaic (PV) system that have been proposed, incremental conductance (INC) and perturb and observe $(\mathrm{P} \& \mathrm{O})$ are the most popular because of their simplicity and ease of implementation. However, under partial shading conditions (PSCs), these MPPT algorithms fail to track the global maximum power point (GMPP) and instead converge into local maximum power points (LMPPs), resulting in considerable PV power loss. This paper presents a new hybrid MPPT technique combining the artificial bee colony $(\mathrm{ABC})$ and $\mathrm{P} \& \mathrm{O}$ algorithms named $\mathrm{ABC}-\mathrm{P} \& \mathrm{O}$. The $\mathrm{P} \& \mathrm{O}$ technique is used to track the MPP under uniform irradiance, and only during irradiance variations is the ABC algorithm employed. The effectiveness of the proposed hybrid algorithm at tracking the GMPP, under both uniform and nonuniform irradiance conditions, was assessed by hardware-in-the-loop (HIL) tests employed by a dc-dc boost converter. Then, the ABC-P\&O strategy was applied to obtain the voltage reference for the outer PI control loop, which provided the current reference to the discrete-time sliding-mode current control. The ABC-P\&O algorithm has a reasonable computational cost, allowing the use of a commercial, low-priced digital signal controller (DSC) with outer voltage and inner current control loops. Many challenging tests validated that the proposed ABC-P\&O technique converges fast to the GMPP with high efficiency and superior performance under different PSCs.
\end{abstract}

Keywords: maximum power point tracking; photovoltaic system; artificial bee colony; hardware-inthe-loop testing; partial shading conditions

\section{Introduction}

Photovoltaic (PV) energy is a promising alternative among the renewable sources that offers several advantages, including clean energy generation, using a renewable/essentially permanent energy source that is freely available, and low maintenance and operational costs. However, the low efficiency of PV systems, often due to their nonlinear electricity generation and variable atmospheric conditions, remains a significant challenge. Therefore, to overcome this drawback, a PV system needs to operate at its maximum power point (MPP) regardless of local atmospheric conditions, such as moving clouds, dust, neighboring buildings, and trees [1].

Numerous different maximum power point tracking (MPPT) techniques have been proposed in the literature over the decades [2-62] (see Figure 1), and fascinating recent review articles about them have been published [1,63-68]. These MPPT techniques can operate around the global maximum power point (GMPP) under normal solar irradiance conditions. However, few can operate during partial shading conditions (PSCs) due to 
the shadows of trees, buildings, or moving clouds that produce limit the solar irradiance reaching PV systems. During PSCs, the bypass diodes connected in parallel with either a single or several photovoltaic solar cells to prevent hot spots on PV modules produce multiple peaks on the P-V curve. Therefore, during PSCs, many of the conventional MPPT techniques cannot track the global maximum power point (GMPP) and may fall into any of the local maximum power points (LMPPs), resulting in reduced output power.

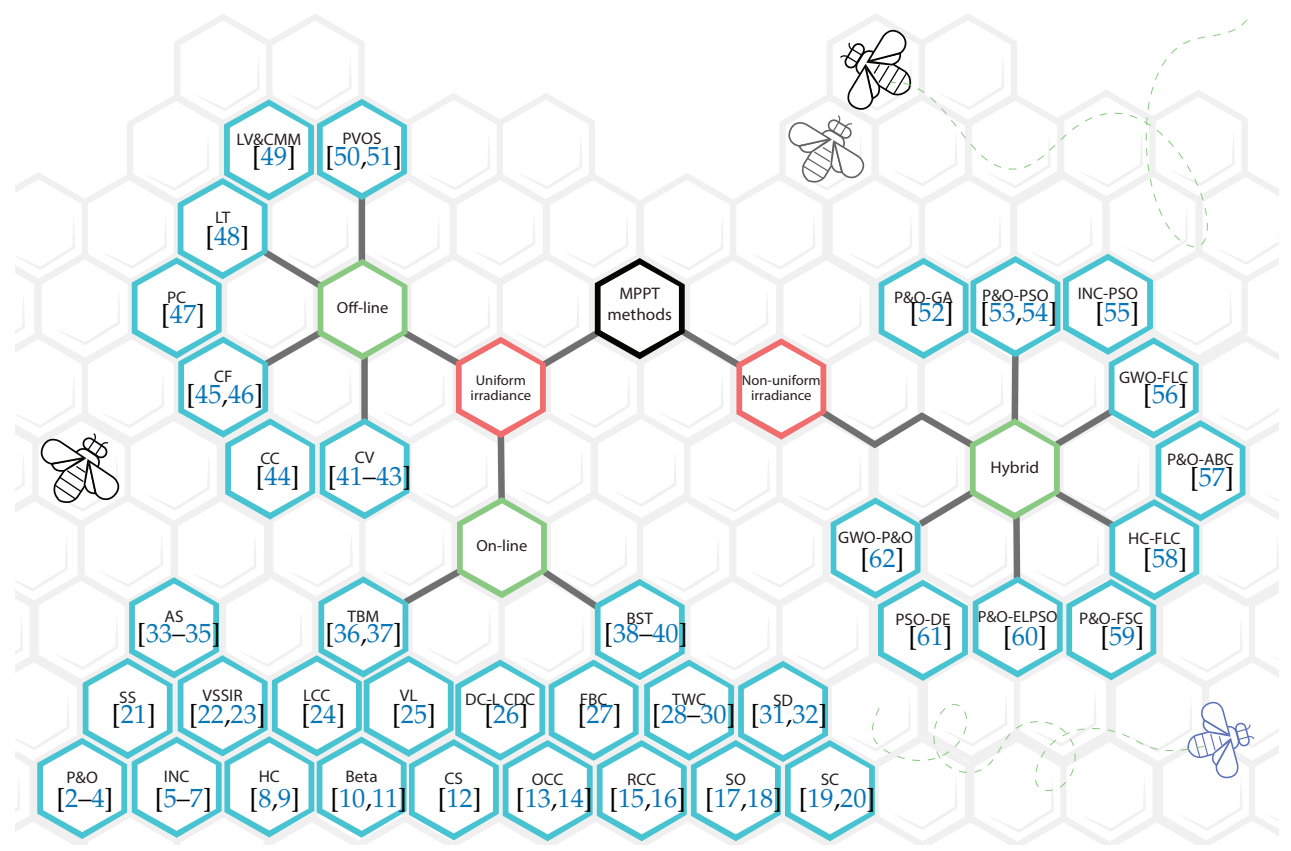

Figure 1. A classification of MPPT techniques (please see the abbreviation section for the full name of each method).

A possible feature with which to classify MPPT techniques is whether each technique operates under uniform and non-uniform irradiance conditions, as shown in Figure 1. According to this classification, the MPPT techniques for uniform irradiance conditions can be divided into online methods and offline methods. These use the instantaneous sensed variables to generate the control signals to track the MPP, unlike the offline or model-based methods, which use previous PV physical information to design the control algorithm [63]. Among the MPPT methods for uniform irradiance conditions, hill climbing $(\mathrm{HC})$ and perturbation and observation $(\mathrm{P} \& \mathrm{O})$ are the commonly used algorithms because of simplicity, ease of implementation, and low cost [58,69]. On the other hand, under PSCs, the classical methods fail to operate at GMPP, and hence there is a need for more advanced optimization (hybrid) algorithms, as shown in Figure 1.

This paper proposes a new MPPT method able to operate under uniform or nonuniform irradiance conditions. The proposed method is a hybrid between the $\mathrm{P} \& \mathrm{O}$ and the artificial bee colony algorithm $(A B C)$ method, named ABC-P\&O. During the system start-up and uniform irradiance conditions, the $\mathrm{P} \& \mathrm{O}$ method is employed to identify the nearest local maximum with a dynamic step size that allows for tracking the MPP more rapidly during the transients, and reduces the oscillations around the MPP in steady-state. On the other hand, during irradiance changes, the $P \& O$ method switches to the $A B C$ technique to search for the most probable current operation point from the 133 different cases available in the $\mathrm{P}-\mathrm{V}$ characteristic data, as shown in Figure 2. Since each of the 133 cases has 24 permutations, the $\mathrm{ABC}$ search universe is represented by a total of 3192 cases that ensure finding the most likely operation point. Once the actual operating point is determined, it is easy to estimate the reference voltage that allows the GMPP for that case. Next, the $\mathrm{ABC}$ technique switches to the $\mathrm{P} \& \mathrm{O}$ method, which uses the reference voltage previously calculated as initialization. 


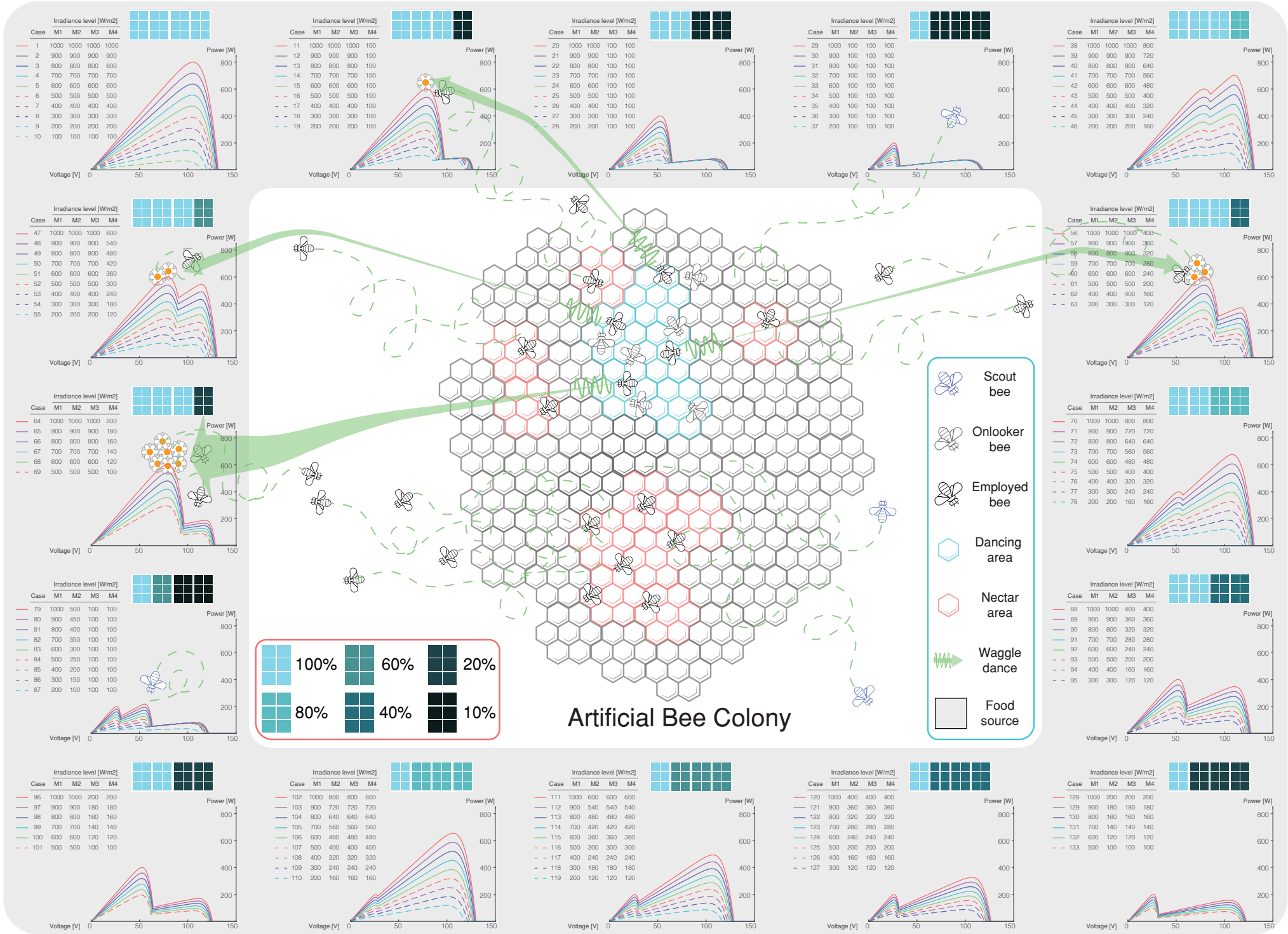

Figure 2. P-V characteristics of four PV modules KC200GT connected in series under uniform and nonuniform irradiance conditions. 
A comparison of the most prominent hybrid MPPT methods to operate under PSCs is listed in Table 1. The major contributions of this work, based mainly on this state-of-the-art review, are listed below.

- $\quad$ Fast convergence method: An innovative method to calculate the GMPP of the PV system through the hybrid ABC-P\&O algorithm, which ensures fast convergence with minimum steady-state oscillations. The soft-computing reported techniques have high computational costs or many iterations where different references are probed during the optimization process. Both cases cause longer convergence times and also produce oscillations in the main converter's variables, as is described in Table 1.

- MPPT algorithm decoupling dynamics from the control loops: Many of the MPPT techniques listed in Table 1 directly regulate the duty cycle, which produces oscillations during every update of the duty cycle in the converter's voltage and current waveforms. Therefore, an appropriate stabilization time is required before using the algorithm again. This problem can be fixed by decoupling the dynamics of the MPPT and the control of the converter by employing a fast current loop, as in the presented ABC-P\&O algorithm. This way, the MPPT reference output corresponds to a voltage instead of a duty cycle, avoiding the steady-state oscillations.

- $\quad$ Fast control loops: Two nested control loops together with a current controller (inner loop) and a voltage controller (outer loop), in combination with the ABC-P\&O MPPT algorithm, permit one to regulate the output voltage of a PV system under challenging environmental circumstances. All the presented controllers guarantee fast-tracking of the control set-points, and low steady-state error under challenging tests, including system start-up, dynamic partial shading changes, and irradiance variations. The implementation of these loops allows the system's independent and fast dynamic response.

- Experimental validation in a low-cost controller: The presented MPPT algorithm and the double loop controller of the dc-dc boost converter were implemented in a commercial low-cost digital signal controller (DSC). This way, the MPPT algorithm was tested in realistic operation conditions, unlike many of the proposed techniques presented in the literature that just have been verified in simulations or experimentally with expensive control platforms, as shown in Table 1.

- A complete experimental validation: The MPPT method was tested by simulation and hardware-in-the-loop (HIL) to prove its viability and superior robustness to obtain the GMPP of the PV system in challenge tests, which included different dynamic partial shading changes, irradiance variations, and start-up tests. It also included comparing the proposed method with a conventional P\&O method, with a voltage scan across the entire voltage range for the PV system to ensure always the GMPPT [70].

The rest of this paper is organized as follows: Section 2 gives a system description. Section 3 describes the presented MPPT approach. Section 4 shows the simulated and hardware-in-the-loop results. Finally, the conclusions are presented in Section 5. 
Table 1. A comparison of hybrid MPPT methods.

\begin{tabular}{|c|c|c|c|c|c|c|c|c|c|c|}
\hline $\begin{array}{l}\text { MPPT } \\
\text { Algorithm }\end{array}$ & Ref. & $\begin{array}{l}\text { MPPT Reference } \\
\text { Output }\end{array}$ & $\begin{array}{l}\text { Converter (Switching } \\
\text { Frequency) }\end{array}$ & $\begin{array}{l}\text { Shading } \\
\text { Patterns }\end{array}$ & Exp. Results & $\begin{array}{l}\text { Low Controller } \\
\text { Cost }\end{array}$ & $\begin{array}{l}\text { Shading Pattern } \\
\text { Changes }\end{array}$ & $\begin{array}{l}\text { Irradiance } \\
\text { Variations }\end{array}$ & $\begin{array}{l}\text { Start-Up } \\
\text { Test }\end{array}$ & $\begin{array}{l}\text { Fast Tracking Speed } \\
\text { without Oscillations }\end{array}$ \\
\hline P\&O-GA & [52] & Duty cycle & Boost $(20 \mathrm{kHz})$ & 8 & & & & & & \\
\hline P\&O-PSO & [53] & Duty cycle & Boost (20 kHz) & 9 & 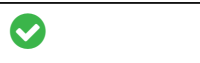 & $v$ & $\checkmark$ & 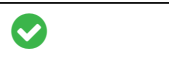 & 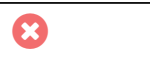 & $x$ \\
\hline INC-PSO & {$[55]$} & Voltage & Without converter & 1 & $x$ & (2) & 8 & (1) & $x$ & $x$ \\
\hline GWO-FLC & [56] & Duty cycle & Boost (?) & 3 & $x$ & (2) & 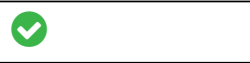 & 8 & $x$ & 8 \\
\hline P\&O-PSO & [54] & Voltage & $\begin{array}{l}\text { Interleaved } \\
\text { Boost } \\
(20 \mathrm{kHz}) \\
\end{array}$ & 3 & 0 & $\vartheta$ & 0 & $\boldsymbol{x}$ & $\theta$ & $\boldsymbol{x}$ \\
\hline $\mathrm{P \& O}-\mathrm{ABC}$ & [57] & Duty cycle & Boost (?) & 3 & $x$ & (2) & (1) & ( & 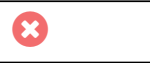 & 8 \\
\hline HC-FLC & [58] & Duty cycle & Boost $(4 \mathrm{kHz})$ & 1 & 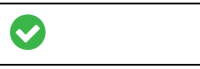 & 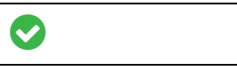 & (1) & 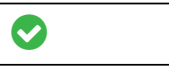 & $x$ & $x$ \\
\hline P\&O-FSC & [59] & Duty cycle & $\begin{array}{l}\text { Buck-boost } \\
(35 \mathrm{kHz})\end{array}$ & 2 & $\vartheta$ & $\boldsymbol{x}$ & x & 8 & $\boldsymbol{x}$ & $\boldsymbol{x}$ \\
\hline P\&O-ELPSO & [60] & Duty cycle & Boost $(10 \mathrm{kHz})$ & 4 & 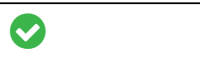 & $v$ & $\checkmark$ & 8 & 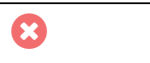 & $x$ \\
\hline PSO-DE & [61] & Duty cycle & Boost (20 kHz) & 3 & 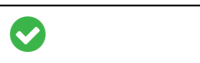 & $x$ & $\theta$ & $x$ & $x$ & $x$ \\
\hline GWO-P\&O & [62] & Duty cycle & Boost $(10 \mathrm{kHz})$ & 5 & 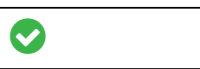 & 8 & 8 & $x$ & x & (x) \\
\hline This work & {$[-]$} & Voltage & Boost $(25 \mathrm{kHz})$ & 133 & 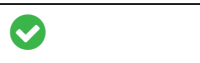 & 8 & 8 & 8 & 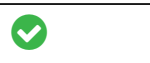 & V \\
\hline
\end{tabular}

V: Yes. (X: No,. (): Only in simulation. (2): Not implemented. (3): Information not found. 


\section{PV System Description}

A setup of four PV modules connected in series with its respective parallel bypass diodes was used to study the nature of the PV string characteristics under uniform and nonuniform irradiance conditions, as shown in Figure 3. This PV string charges a battery employing a dc-dc boost switching converter with a nested control loop in charge of tracking the PV system's MPP. The MPPT algorithm and the double loop controls are presented in Figure 3. The PV units modeled by PLECS correspond to an array of four series-connected KC200GT solar modules. Their electrical nature is displayed in Table 2. The non-linear $\mathrm{P}-\mathrm{V}$ characteristics for 133 different cases of shading patterns are shown in Figure 2. Each of the 133 cases has 24 possible permutations, which means a total of 3192 possible PSCs. This way, it was possible to study the PV system under uniform irradiance levels (cases from 1 to 10) with a unique peak in the $\mathrm{P}-\mathrm{V}$ curve, which corresponds with the GMPP. Figure 2 also shows the nonuniform irradiance levels over the PV modules, which produce different combinations of PSCs. These PSCs generate a P-V curve with multiple peaks, from two to three; the GMPP positions indicate the LMPP changes in different situations with the MPPT algorithms.

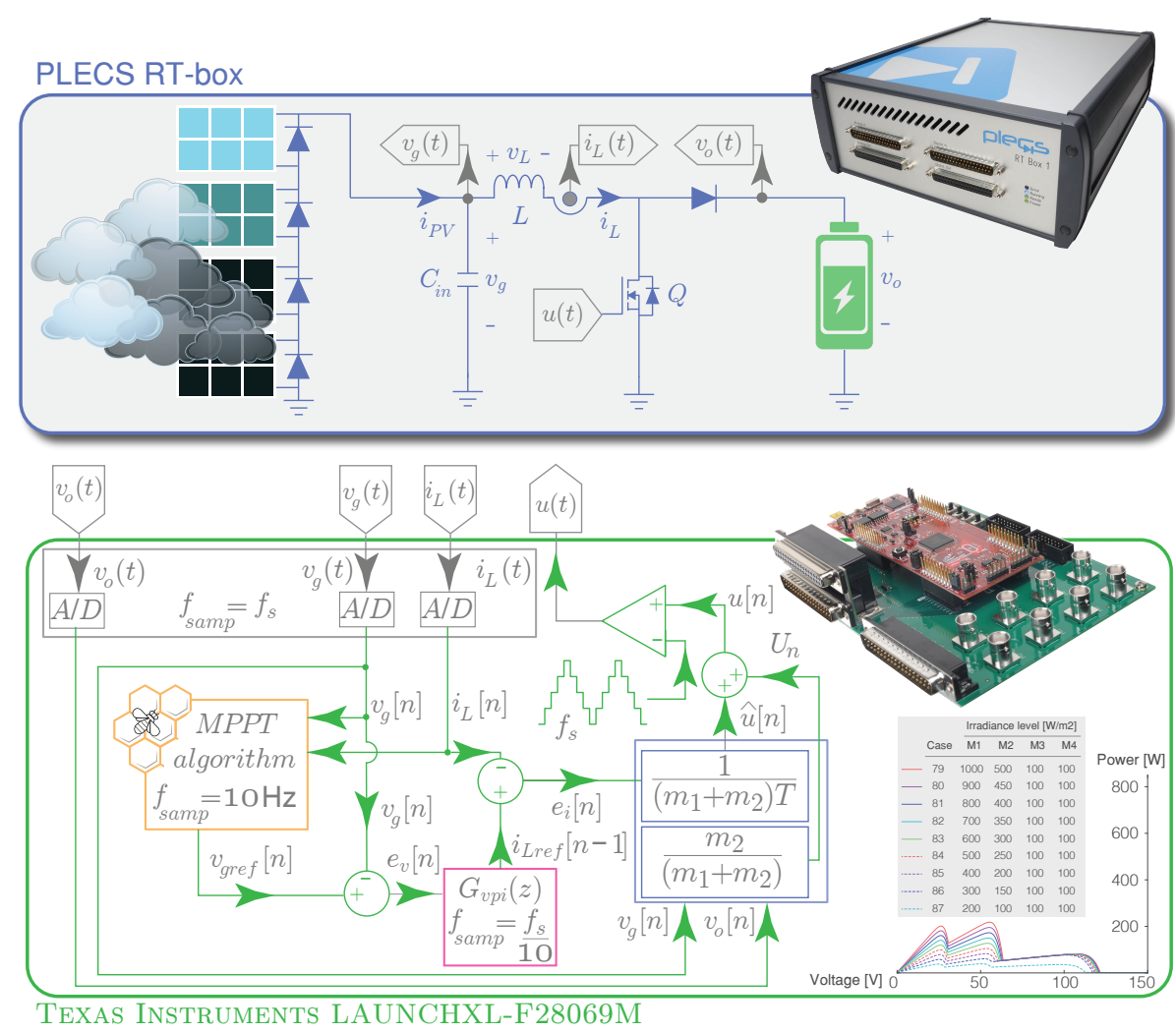

Figure 3. Block diagram of the digital controller for the MPPT of the boost converter.

Table 2. Electrical characteristics of the PV module KC200GT.

\begin{tabular}{ll}
\hline Electrical Parameters & Value \\
\hline Maximum power $P_{\max }$ & $200.143 \mathrm{~W}$ \\
Voltage at maximum power $V_{m p}$ & $26.3 \mathrm{~V}$ \\
Current at maximum power $I_{m p}$ & $7.61 \mathrm{~A}$ \\
Short-circuit current $I_{s c}$ & $8.21 \mathrm{~A}$ \\
Open-circuit voltage $V_{o c}$ & $32.9 \mathrm{~V}$ \\
Temperature coefficient of short-circuit current & $3.18 \times 10^{-1} \mathrm{~A} /{ }^{\circ} \mathrm{C}$ \\
Temperature coefficient & $-1.23 \times 10^{-1} \mathrm{~V} /{ }^{\circ} \mathrm{C}$ \\
\hline
\end{tabular}


The differential equations for the boost converter are:

$$
\begin{aligned}
& \frac{d i_{L}(t)}{d t}=\frac{v_{g}-(1-u) v_{o}}{L} \\
& \frac{d v_{o}(t)}{d t}=\frac{-v_{0}}{R_{L} C}+\frac{(1-u) i_{L}}{C},
\end{aligned}
$$

with $i_{L}$ being the inductor current, $v_{0}$ the output voltage, and $u$ the control variable $\in\{0,1\}$. The duty cycle for the boost converter is:

$$
\bar{u}=1-\frac{\bar{v}_{g}}{\bar{v}_{o}} .
$$

\subsection{Discrete-Time Sliding-Mode Current Control}

This section presents the design of the inner loop for the dc-dc boost converter; the strategy used was the discrete-time sliding mode current control (DSMCC) with a fixed frequency. This control has been implemented for switching systems in [71-73]. This strategy realizes a direct digital design, using a discrete time inductor current representation. Therefore, the advantage of the DSMCC is that it can be easily implemented with standard microcontrollers. In this strategy, the variable control $u[n]$ is computed in the $n$-th time sample period to ensure the control surface (4) is reached in the next sampling period $\left(f_{\text {samp }}=f_{s}\right)$.

$$
s[n]=i_{\text {Lref }}[n-1]-i_{L}[n] .
$$

The inductor current slopes of the boost converter can be calculated using (2), thereby obtaining the results listed in Table 3. The Euler approximation takes the averaged model of the converter's inductor current slope $\frac{d i_{L}}{d t} \approx \frac{i_{L}[n+1]-i_{L}[n]}{T}$ into account and leads to the following discrete-time inductor current expression:

$$
i_{L}[n+1]=i_{L}[n]+T\left(m_{1}+m_{2}\right) u[n]-m_{2} T
$$

where $T$ is the switching or sampling period. Hence, the resulting expression of the duty cycle is

$$
u[n]=\frac{1}{\left(m_{1}+m_{2}\right) T} e[n]+\frac{m_{2}}{m_{1}+m_{2}},
$$

where $e[n]=i_{\text {Lref }}[n]-i_{L}[n] ; i_{\text {Lref }}[n]=i_{L}[n+1]$ (see Figure 3). Using the expressions for $m_{1}$ and $-m_{2}$ for the output current slopes from Table 3 in (6), the control law for the boost converter is given by:

$$
u[n]=\frac{L}{v_{o}[n] T} e[n]+1-\frac{v_{g}[n]}{v_{o}[n]}
$$

Table 3. Slope of the inductor current waveform.

\begin{tabular}{lcc}
\hline Converter & $m_{\mathbf{1}}$ & $-\boldsymbol{m}_{\mathbf{2}}$ \\
\hline Boost & $\frac{v_{g}}{L}$ & $\frac{v_{g}-v_{0}}{L}$ \\
\hline
\end{tabular}

\subsection{Discrete-Time PI Voltage Control}

For the external loop, a proportional-integrator controller is used to regulate the input voltage of the boost converter $v_{g}$, where the controller transfer function can be expressed in the $\mathrm{z}$ domain using the forward Euler method, as follows:

$$
G_{v p i}(z)=K_{p v}+\frac{K_{i v} T_{s a m p}}{z-1}
$$


where $T_{\text {samp }}=1 / f_{\text {samp }}$, and

$$
K_{p v}=2 \pi C_{i n} f_{c}
$$

and

$$
K_{i v}=\frac{K_{p v}}{T_{i}}
$$

where $C_{i n}$ is the input capacitor, and the value of the crossover frequency $(\mathrm{CF})$ for the voltage loop $\left(f_{c}\right)$ should be lower than the $\mathrm{CF}$ for the current loop. The location of the PI zero should be lower than $f_{c}\left(1 /\left(2 \pi T_{i}\right)<f_{c}\right)$.

\section{ABC-P\&O Algorithm}

This paper proposes a hybrid strategy between the well-known perturb and observe $(\mathrm{P} \& \mathrm{O})$ and the artificial bee colony $(\mathrm{ABC})$ to track the GMPP of a PV system.

The $\mathrm{P} \& \mathrm{O}$ algorithm aims to provoke perturbations by either decreasing or increasing the reference voltage while observing the output power PV system. If the current measured power $P[n]$ is greater than its previous sampled value $P[n-1]$, the voltage reference change continues in the same direction. Otherwise, it is reversed. The PV module voltage is compared with the maximum voltage to predict the MPP [74]. Following this, a small step of reference voltage results in a power step of the PV module [75]. In the proposed MPPT algorithm, the $\mathrm{P} \& \mathrm{O}$ is used during the system start-up and under uniform solar irradiance. In addition, the reference voltage step changes dynamically to ensure a fast track of the MPP during transients and low power oscillations during the steady-state.

On the other hand, the artificial bee colony $(\mathrm{ABC})$ is motivated by the foraging behavior of honey bee colonies [76,77]. A new method to determine the MPP of the PV module, based on the ABC algorithm under uniform irradiance levels, is presented in [78]. This work is an extension of the previous one that allows operation under PSCs through hybridization with an offline MPPT algorithm such as the P\&O strategy. In the ABC-P\&O algorithm, the $\mathrm{ABC}$ is employed only during irradiance variations to search the voltage reference that ensures the GMPP initializes the $\mathrm{P} \& \mathrm{O}$ algorithm.

The concept of the proposed ABC algorithm is explained below. Three bee types are presented in Figure 2: the employed bees, the onlooker bees, and the scout bees. The employed bees seek food sources, those being pollen and nectar. The proposed algorithm corresponds to the dataset of the $\mathrm{P}-\mathrm{V}$ characteristic curves. The employed bees now know the actual operating point of the PV module, which fits with the voltage $\left(v_{g}[n]\right)$ and the current $\left(i_{L}[n]\right)$, and so the food source exploration begins. The amount of nectar for the various food source locations is shared by the employed bees to the onlooker bees through waggle dance movements. The onlooker bees pick out the food source depending on the prediction associated with its amount of nectar. During the greedy search process, they retain only the maximum food source location in their memory. Once an employed bee food source is completely exploited, that employed bee turns into a scout bee and goes to explore a new place. The food source location with the maximum nectar is determined by comparing the probability factor associated with various food locations. Finally, the improved solution determines the curve of all the 133 in the dataset with the higher probability of an equivalent operation point (see Figure 2). When the curve is selected, the value of the voltage $\left(v_{\text {gref }}[n]\right)$ at the maximum power can be established by means of a lookup table. Therefore, the ABC system combines local search methods, carried out by employed and onlooker bees, with global search methods, managed by onlookers and scouts, attempting to balance exploration and exploitation.

To implement the ABC MPPT algorithm, a dataset of the P-V characteristic curves shown in Figure 2 is defined to generate the optimal voltage reference for the maximum power solutions. By stating a vector with the possible values for the voltage of the PV module, each solution for the voltage reference is produced:

$$
\mathbf{V}_{\mathbf{g}}=\left\{v_{g 1}, v_{g 2}, v_{g 1}, \ldots, v_{g i}\right\}
$$


and $v_{g i}$ represents the $i^{t h}$ solution. The probability for the powers of all the characteristic curves corresponding to the input voltage $v_{g}[n]$ are calculated as [79]:

$$
\mathbf{P}=\frac{P_{p v_{Q}}}{\sum_{Q=1}^{N} P_{p v_{Q}}}
$$

Therefore, the vector $\mathbf{P}$ includes $N$ probabilities of all characteristic curves corresponding to the $i^{\text {th }}$ location for the sample voltage $v_{g}[n]$. To find the probability function (12), a new solution $n e w v_{g}$ is generated using [79]:

$$
n e w v_{g}=v_{g i}+\phi_{i}\left(v_{g i}-v_{g}\right)
$$

where $\phi_{i}$ is a random number between -1 and 1 . Afterwards, a local search around the selected newvg is executed, and this depends on the calculated probability $\mathbf{P}$ and its actual probability power $P_{a}=P_{p v}[n] / \sum_{\mathrm{O}=1}^{N} P_{p v_{\mathrm{O}}}$. The current operating curve of the PV module is determined by the position of the value of the probability $\mathbf{P}$ nearest to the probability $P_{a}$. It is possible to determine the maximum voltage of each curve after the operating curve is determined, and then set the voltage $V_{m}$ for maximum power $P_{m}$. The proposed hybrid algorithm $\mathrm{ABC}-\mathrm{P} \& \mathrm{O}$ employs the $\mathrm{P} \& \mathrm{O}$ to start-up the algorithm. After the start-up, the ABC MPPT algorithm is executed if there is a variation in power of the PV array due to solar irradiation changes subjected to a reference $\Delta P(\%)$ value [80], defined as:

$$
\frac{\left|P_{\text {pvnew }}-P_{\text {pvlast }}\right|}{P_{\text {pvlast }}} \geq \Delta P_{p v}(\%),
$$

where $P_{\text {pvlast }}$ is the previous power measurement and $P_{\text {pvnew }}$ is the actual power measurement. During the ABC algorithm, every employed bee proposes a new solution newvg using (13), and afterwards, calculates the probability values $\mathbf{P}$. The employed bees share through waggle dances the information of their food sources with the onlooker bees. A solution $v_{g}$ is selected by every onlooker bee depending on $\mathbf{P}$ and $P_{a}$. In the case of an abandoned solution for the scout bee, the replacement with the new solution will be randomly made. Once the solution $v_{g}$ is selected by the $\mathrm{ABC}$ algorithm, the found reference voltage solution is the starting voltage reference for the $\mathrm{P} \& \mathrm{O}$ algorithm. The GMPP search will again execute if the condition (14) is satisfied. This condition ensures that the ABC algorithm is executed to detect the optimal voltage solution for the GMPP even if there is any change in solar irradiance. The entire search process for GMMP of the proposed ABC-P\&O MPPT algorithm is shown in Algorithm 1. In addition, a general flow chart of the proposed GMPPT is shown in Figure 4.

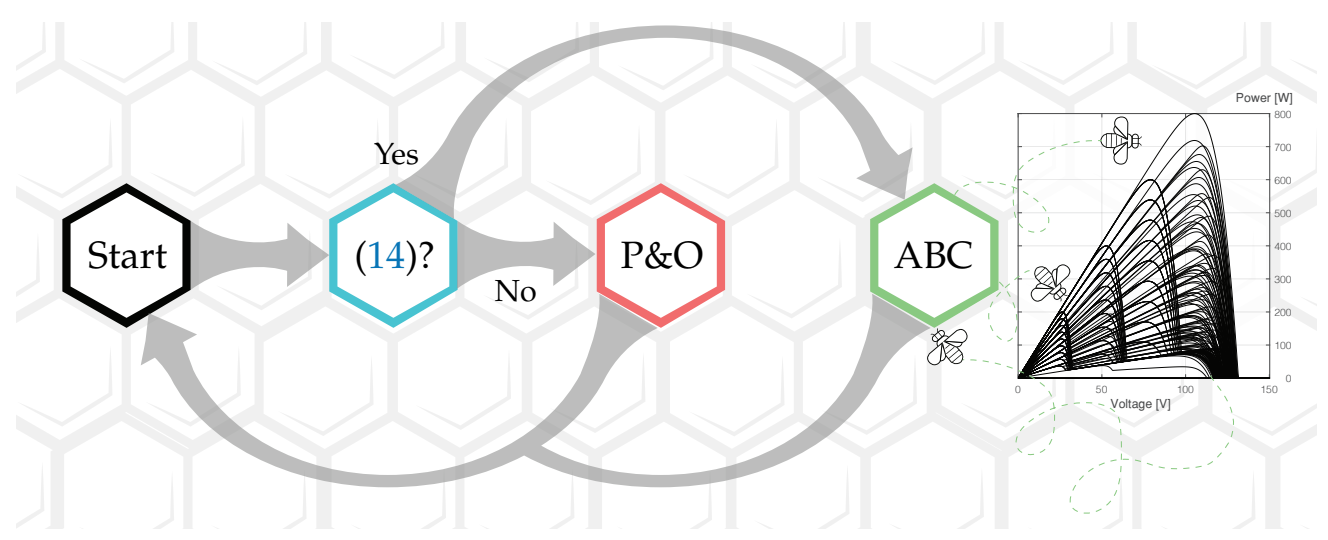

Figure 4. General flowchart of the ABC-P\&O MPPT algorithm based on Algorithm 1. 


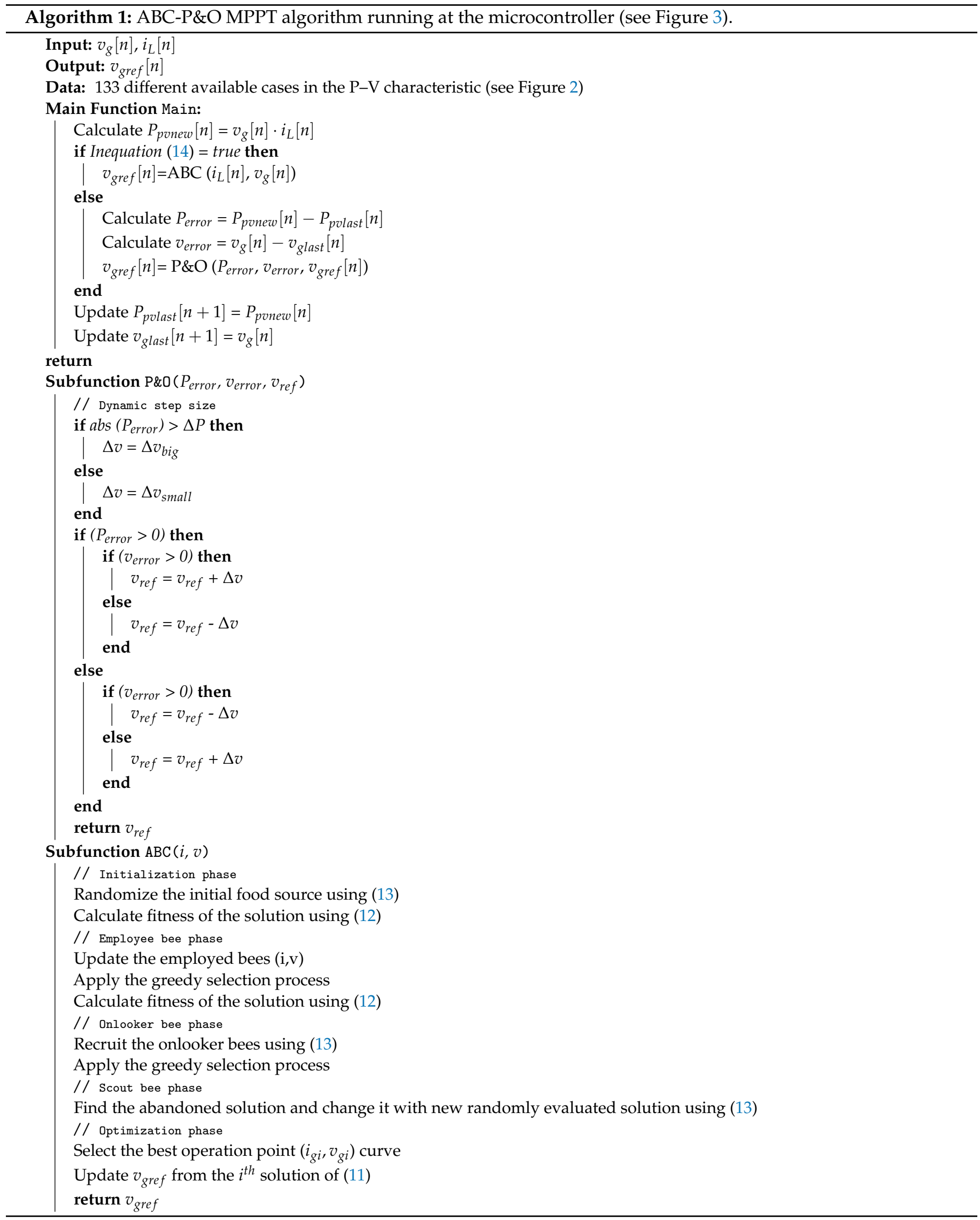




\section{Results}

Hardware-in-the-loop (HIL) results are presented in this section to evaluate the effectiveness of the ABC-P\&O MPPT algorithm employing a dc-dc boost converter. The stage power converter and the PV array were implemented through PLECS RT Box 1, with the sampled time to model the converter being $6.6 \mu \mathrm{s}$. The values of the boost converter components were: $L=1 \mathrm{mH}, C_{i n}=200 \mu \mathrm{F}$, $f_{s}=25 \mathrm{kHz}$, and $V_{o}=160 \mathrm{~V}$. The different controls of the PV global system control scheme, as shown Figure 3, were implemented using TI 28069M LaunchPad, a low-cost Texas Instrument microcontroller. Figure 5 shows the setup for HIL experiments.

The proposed ABC-P\&O MPPT method is compared with a GMPPT P\&O algorithm based on the work [70], which consists of using a stage to determine that a partial shading situation occurs. A voltage sweep was performed in partial shading conditions across the entire voltage range (from 0 to the open voltage value) of the PV system. The voltage reference that produces the maximum power was used to initialize after the voltage sweep with the P\&O algorithm.

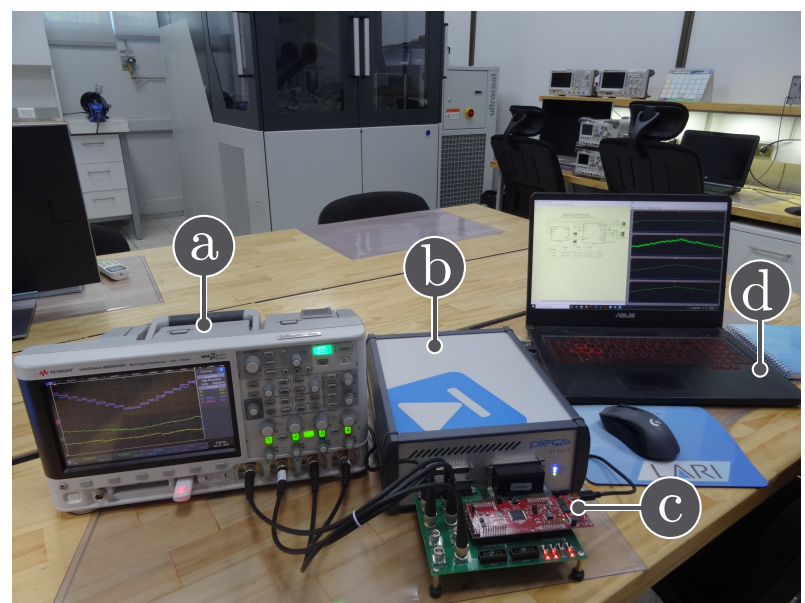

Figure 5. The experimental setup of the hardware in-the-loop tests: (a) oscilloscope, (b) PLECS RT-box, (c) Texas Instruments LAUNCHXL-F28069M, (d) laptop.

\subsection{Inner Loop Current Control Results}

Current loop time domain responses for the inductor current of the boost converter are presented in this subsection, and the results are shown in Figure $6 . v_{g}, v_{0}$, and $i_{L}$ were the signals sampled for the control, and the sampling time was $500 \mu \mathrm{s}$. The current reference was modified from 4 to $8 \mathrm{~A}$ and back to $4 \mathrm{~A}$, as can be seen in Figure $6 \mathrm{a}, \mathrm{b}$. The input voltage was set to $100 \mathrm{~V}$, and the output voltage was $V_{o}=160 \mathrm{~V}$ to ensure a boost operation. The transitions during reference changes were smooth, without overshoot and settling times near to $250 \mu \mathrm{s}$. As shown, the inductor current was well regulated. The inductor currents followed the change in the current reference perfectly. Thus, during the current step reference change, the current control performance was verified.

\subsection{Double Loop Results}

For external loop validation, Voltage reference variations from 100 to $110 \mathrm{~V}$ were considered, with a step between variations of 5 V. HIL test responses are displayed in Figure $6 \mathrm{c}$. The selected crossover frequency (CF) corresponds to $f_{c}=500 \mathrm{~Hz}$, which allows the proportional gain calculation according to (9). The location of the PI zero of Equation (10) is lower than $f_{\mathcal{c}}\left(1 /\left(2 \pi T_{i}\right)<f_{c}\right)$ whereby a $T_{i}=3.18 \times 10^{-3} \mathrm{~s}$ was selected. Figure 3 shows how the voltage regulator $\left(G_{v p i}(z)\right)$ calculates the inductor current reference every $400 \mu \mathrm{s}$. As shown in Figure $6 c$, the current transitions caused by the voltage changes were smooth, and the voltage reference was strictly tracked. 


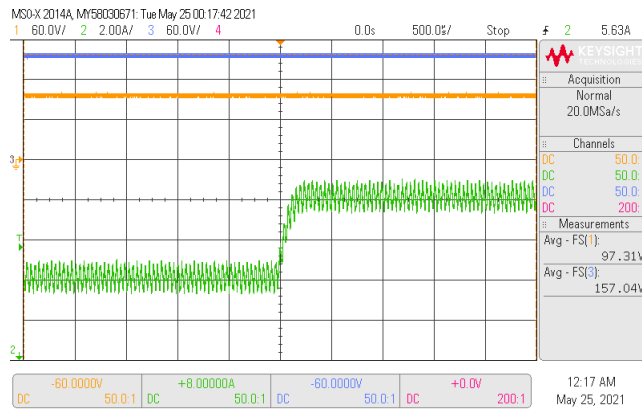

(a)

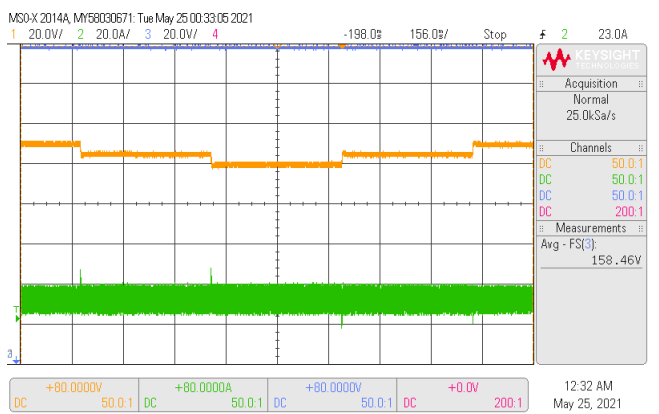

(c)

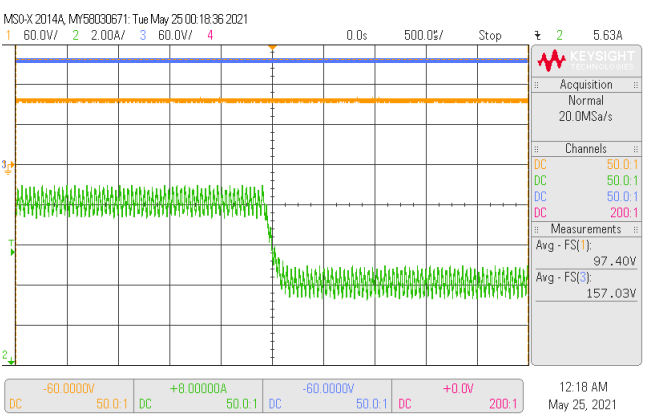

(b)

Figure 6. Experimental $(\mathbf{a}, \mathbf{b})$ responses of the sliding digital current input control when the reference $i_{r e f}$ : (a) changes from 4 to $8 \mathrm{~A}$, and (b) from 8 to $4 \mathrm{~A}$. The converter operated with an input voltage $V_{g}=100 \mathrm{~V}$ and an output voltage $V_{o}=160 \mathrm{~V}$. CH1: $V_{g}(60 \mathrm{~V} / \mathrm{div}), \mathrm{CH} 2: V_{o}(60 \mathrm{~V} / \mathrm{div}), \mathrm{CH}: i_{L}$ (2A/div), and a time base of $500 \mu \mathrm{s}$. (c) Responses of the double loop using sliding digital current control when the reference $v_{\text {ref }}$ changed with steps of $5 \mathrm{~V}$ between 100 and $115 \mathrm{~V}$ while the output voltage $\left(V_{o}=160 \mathrm{~V}\right)$ ensured a boost operation. CH1: $\left.v_{g}(20 \mathrm{~V} / \mathrm{div}), \mathrm{CH} 2: V_{o} 20 \mathrm{~V} / \mathrm{div}\right), \mathrm{CH} 3: i_{L}$ (20 A/div), and a time base of $156 \mathrm{~ms}$.

\subsection{GMPPT PEO and Proposed ABC-PEO Method Comparison}

To compare the proposed method with the GMPPT P\&O implemented in [70], the GMPPT algorithms were executed to render a new voltage reference for the voltage loop, every $100 \mathrm{~ms}$, as shown in Figure 3 for the GMPPT algorithm block. For the ABC MPPT, $\triangle P(\%)$ was programmed to $25 \%$, and its parameters were 133 food sources and a beehive composed by 34 onlooker bees and 34 employed bees. An important aspect determining the feasibility of a control algorithm is the associated computational burden. Therefore, the computation time for the ABC MPPT when a radiance change occurred was $23.73 \mathrm{~ms}$. However, the hurdle of the proposed ABC MPPT method is its implementation in a low-cost DSC, given the fact that it is a procedure with high computational requirements. As stated in Figure 3, the inner current loop updated at $25 \mathrm{kHz}$ in the DSC, the outer voltage loop was calculating at $2.5 \mathrm{kHz}$, and the MPPT strategy was computing at $10 \mathrm{~Hz}$. Even though the scale time differences between the systems are challenging, it also presents advantages to implementing an MPPT based on a finite-state machine. In this instance, the total code of the ABC MPPT method was divided into 2500 substatus that were calculated at the inner current loop frequency, to be updated at the MPPT frequency. As can be seen, the MPPT strategy computed at $10 \mathrm{~Hz}$, allowing fair comparisons with the GMPPT P\&O. Additionally, the little pieces of code that constitute each state machine can be computed at each loop iteration together with the voltage and current loops, avoiding over computations in the low-cost DSC. For the validation of the proposed algorithm, six scenarios with different transients of the cases presented in Figure 2 are described below.

\subsubsection{Scenario 1: System Start-Up}

This scenario studies the MPPT techniques during the start-up with the panels' irradiance levels corresponding to case 56 of Figure 2. In Figure 7, the transient behavior from zero current to an equilibrium point, which corresponds to the maximum power for case 56 , is shown, where three modules have an irradiance of $1000 \mathrm{~W} / \mathrm{m}^{2}$ and a module of $400 \mathrm{~W} / \mathrm{m}^{2}$. In Figure 7 both GMPPT 
algorithms reach the steady-state close to $1.3 \mathrm{~s}$, with the proposed MPPT having a uniform step voltage reference to tracking the MPP $(599.9 \mathrm{~W}$ at $79.1 \mathrm{~V})$ through system start-up. It is necessary to notice that the proposed ABC-P\&O algorithm works at the optimum point, without oscillation, as is shown in the input voltage signal after it has been tracked. Due to the GMPPT P\&O realizing a sweep of voltage, the reference voltage was increased until $120 \mathrm{~V}$ to find the GMPPT at $79.1 \mathrm{~V}$. A quantitative analysis of the proposed GMPPT method is presented in Figure 8, and in Figure 7 the GMPPT P\&O method's results are shown. These values confirm similar performances for both methods through the start-up. Due to the fact that the mean power tracked value is closer to the global power maximum, the GMPPT P\&O algorithm had a higher tracking factor.

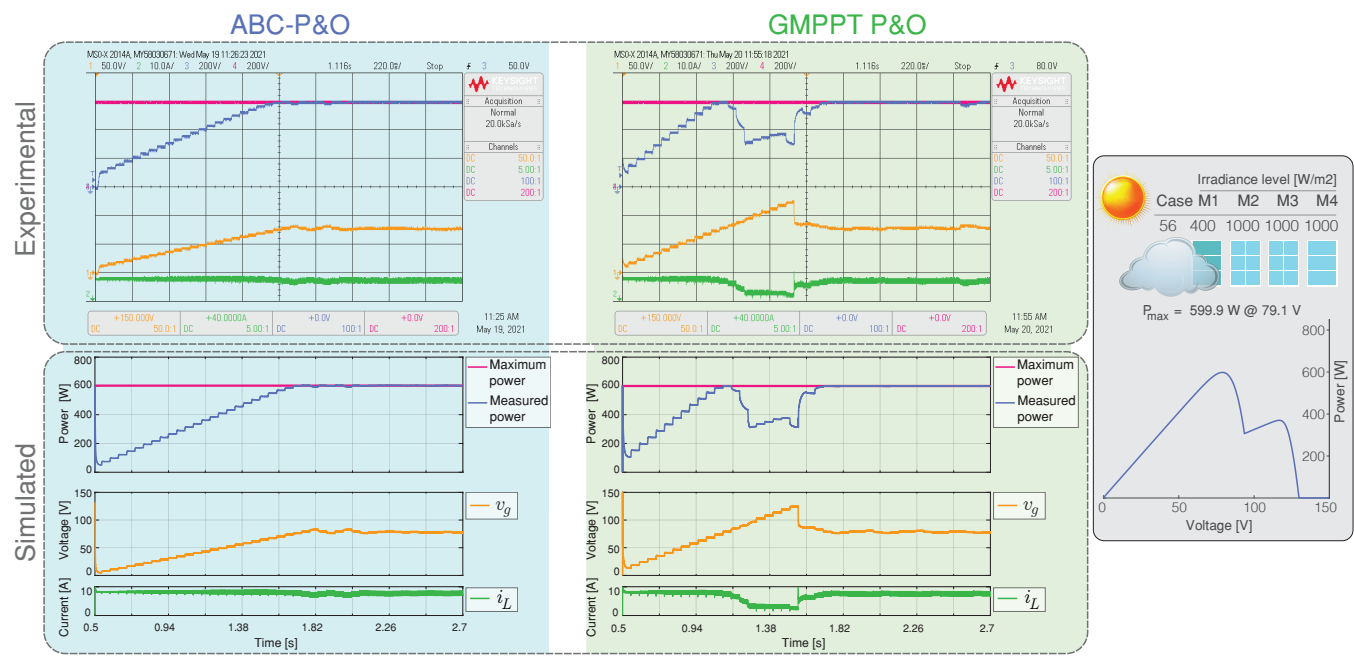

Figure 7. Simulated and experimental dynamic behavior of the MPPT algorithms for Scenario 1 and an output voltage $V_{o}=160 \mathrm{~V}$. The proposed MPPT algorithm (left) is compared with GMPPT P\&O (right). CH1: $v_{g}(50 \mathrm{~V} /$ div $), \mathrm{CH} 2: i_{L}(10 \mathrm{~A} /$ div $), \mathrm{CH} 3:$ maximum power $(200 \mathrm{~W} / \mathrm{div}), \mathrm{CH} 4:$ measured power $(200 \mathrm{~W} / \mathrm{div})$, and a time base of $220 \mathrm{~ms}$.

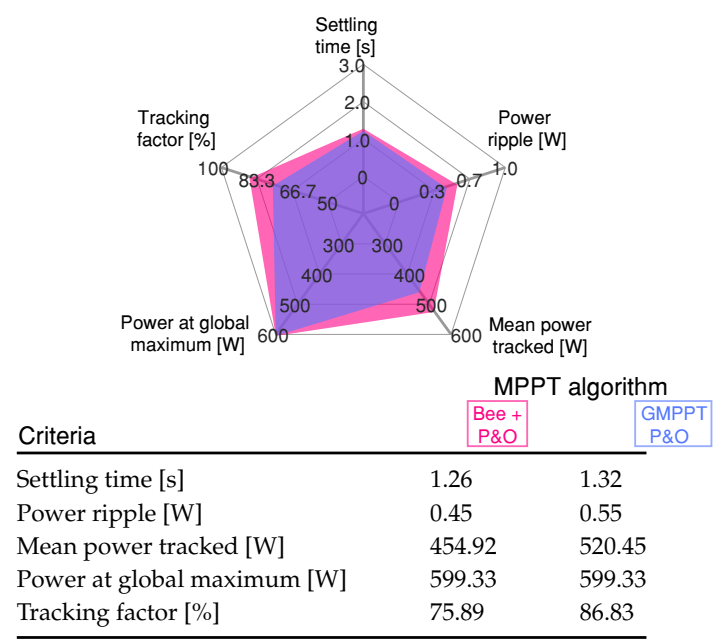

Figure 8. Comparative analysis of the MPPT methods for Scenario 1 shown in Figure 7.

\subsubsection{Scenario 2: Uniform Irradiance Variations}

Scenario 2 studied the MPPT techniques under uniform irradiance variations, as shown in Figure 9. The irradiance sequence corresponded to cases 1,3, 5, 7, and 9 shown in Figure 2. The proposed algorithm quickly identified the optimal voltage reference for the case and tracked the MPP faster, whereas the GMPPT P\&O had slow convergence. In Figure 10 the sensitivities of the MPPT algorithms are shown by means of relative error (RE), absolute error (MAE), and root mean square error (RMSE) for the results presented in Figure 9. 


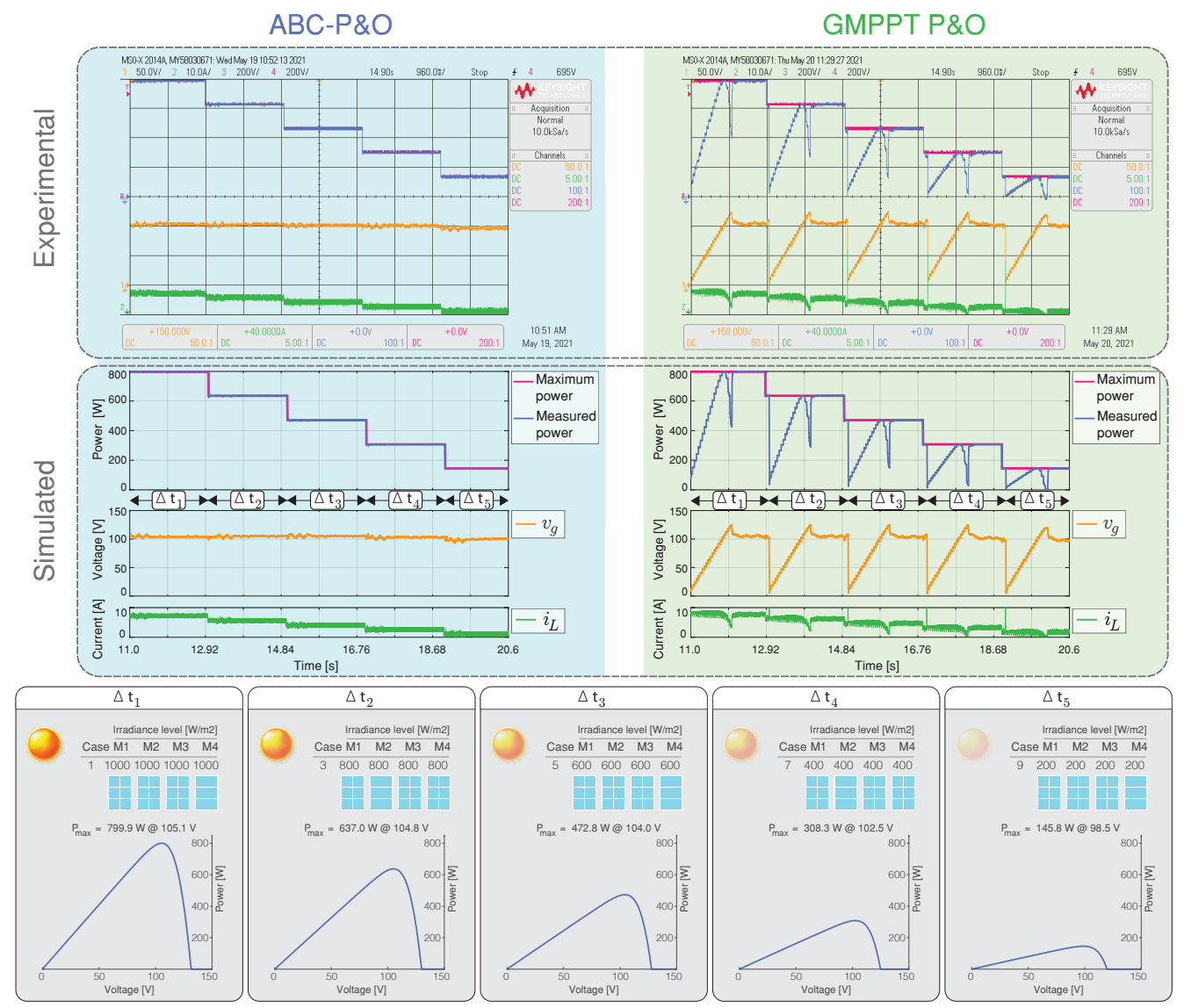

Figure 9. Simulated and experimental dynamic behavior of the MPPT algorithms for Scenario 2 with an output voltage $V_{o}=160 \mathrm{~V}$. The proposed MPPT algorithm (right) is compared with the GMPPT P\&O algorithm (right). CH1: $v_{g}(50 \mathrm{~V} / \mathrm{div}), \mathrm{CH} 2: i_{L}(10 \mathrm{~A} / \mathrm{div}), \mathrm{CH} 3:$ maximum power $(200 \mathrm{~W} / \mathrm{div})$, $\mathrm{CH} 4$ : measured power (200 W/div), and a time base of $960 \mathrm{~ms}$.

$P_{p v i}$ stands for the measured power of the PV module, $m$ is the total number of sampling data, and $P_{m p p}$ is the available MPP power of the solar module. Standard error values indicate that the proposed MPPT algorithm had higher effectiveness in tracking the maximum power point. This statistical analysis shows that the ABC-P\&O method achieved a lower value for the error compared to the GMPPT P\&O algorithm. The proposed ABC-P\&O algorithm resulted in a tracking factor of $99.97 \%$, and for the GMPPT P\&O method, the tracking factor was $80.39 \%$.

\subsubsection{Scenario 3: Sharp Change of the PSC}

Scenario 3 presents a sharp change between case 103 and case 68, producing high PV power variations from 588 to $355 \mathrm{~W}$. Simulated and HIL results of the GMPP tracking performance are presented in Figure 11. The overall MPPT tracking efficiency for the GMPPT P\&O method was $76.65 \%$, unlike the $95.57 \%$ achieved by the ABC-P\&O proposed method (see Figure 12 ). For the GMPPT P\&O method, the PV array always operates in an oscillating mode, as can be observed by the inductor current and input voltage of the converter in Figure 11. 


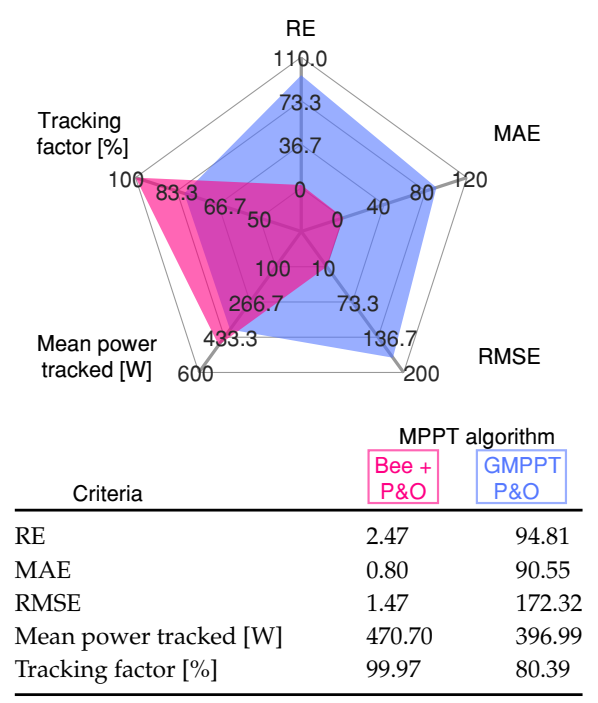

Figure 10. Comparative analysis of the MPPT methods under different uniform irradiance conditions for Scenario 2 shown in Figure 9.

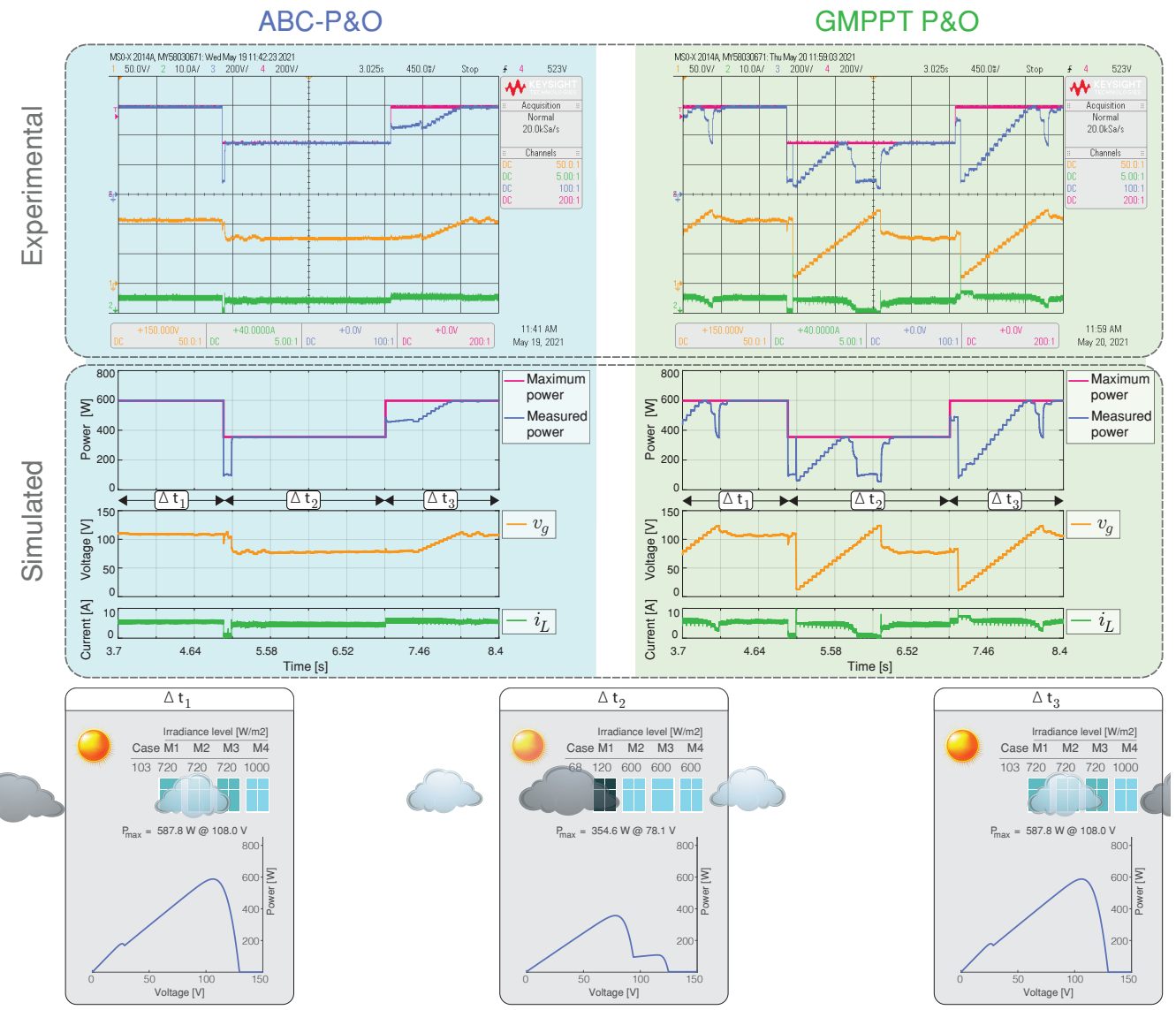

Figure 11. Simulated and experimental dynamic behavior of the MPPT algorithms for Scenario 3 with an output voltage $V_{o}=160 \mathrm{~V}$. The proposed MPPT algorithm (right) is compared with the GMPPT P\&O algorithm (right). CH1: $v_{g}(50 \mathrm{~V} / \mathrm{div}), \mathrm{CH} 2: i_{L}(10 \mathrm{~A} / \mathrm{div}), \mathrm{CH} 3:$ maximum power (200 W/div), CH4: measured power (200 W/div), and a time base of $450 \mathrm{~ms}$.

Consequently, the suggested GMPPT method had superior performance during abrupt irradiation variations compared to the GMPPT P\&O method. Note that during the change from case 68 to 103 , the ABC-P\&O algorithm did not estimate an optimal reference voltage. Nonetheless, when P\&O operated, GMPPT was achieved, demonstrating the robustness of the ABC-P\&O method. 


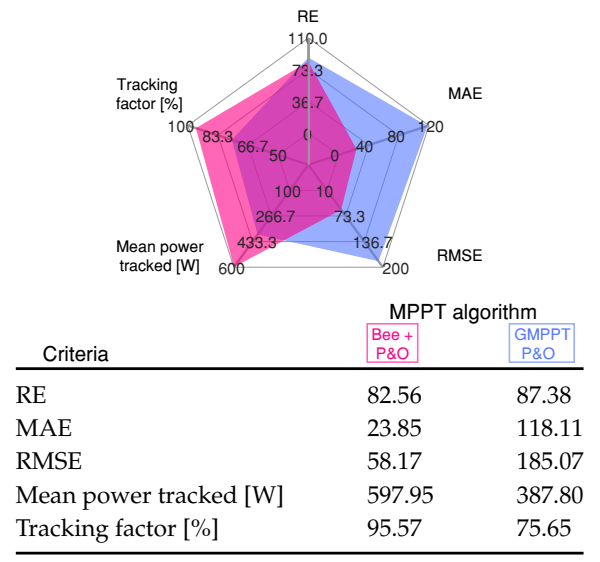

Figure 12. Comparative analysis of the MPPT methods for Scenario 3 shown in Figure 11.

\subsubsection{Scenario 4: Multiple Peaks in the P-V Characteristic}

Scenario 4 presents the sequence of case 3 with only one peak (GMPP), case 52 with two peaks (one GMPP and one LMPP), and case 85 with three peaks (one GMPP and two LMPP) in regard to the $\mathrm{P}-\mathrm{V}$ characteristic. The experimental and simulated results for each MPPT algorithms are shown in Figure 13. For case 3, the irradiance was uniform with a unique MPP at 104.28 V, which was tracked faster by the proposed algorithm. When the irradiance changed in case 52 , there were two peaks; the proposed algorithm identified and tracked the second peak at $77.6 \mathrm{~V}$, much faster than GMPPT P\&O. Finally, when the irradiation was changed in case 85, there were three peaks; the algorithm quickly identified and tracked the second peak $(55.3 \mathrm{~V}, 81.3 \mathrm{~W})$ as the GMPP. ABC-P\&O presented an overall GMPPT tracking efficiency of $97.53 \%$ during Scenario 4 . The GMPPT P\&O method achieved a tracking efficiency of $79.85 \%$. The results for the sequence of cases were evaluated using the standard errors, and the scores of mean power tracked and tracking factor, as shown in Figure 14. This figure reveals that the proposed GMPPT method has strong MPP tracking regarding the GMPPT P\&O method under multiple peaks in the P-V characteristic due to different PSCs.

\subsubsection{Scenario 5: Dark Cloud Passing}

A dark cloud passed in this scenario, obscuring each one of the PV modules. The sequence of the cases included in this scenario was cases 7, 17, 26, and 35, as it is presented in Figure 15.

Cases 17, 26, and 35 correspond to PSC, which has two peaks, and the proposed GMPPT correctly identified the optimal voltage for the maximum power point for the transitions between cases 7,17 , and 26 . Nevertheless, the reference voltage value for case 35 was incorrectly identified by the ABC-P\&O algorithm. This was because of the similar power between the GMPP $(77.1 \mathrm{~W}$ at $26.1 \mathrm{~V})$ and the LMPP located in the second peak $(72.26 \mathrm{~W}$ at $100 \mathrm{~V})$. The proposed MPPT algorithm tracked the GMPP much faster than the GMPPT P\&O algorithm. Figure 16 shows the standard error and comparison indicators for the results presented in Figure 15. The ABC-P\&O algorithm resulted in smaller error values in comparison with the GMMP P\&O method. The ABC-P\&O algorithm resulted in a tracking factor of $98.73 \%$; the GMPPT P\&O method resulted in a tracking factor of $72.295 \%$.

\subsubsection{Scenario 6: Light Cloud Passing}

In this scenario a light cloud passed, partially obscuring the PV modules one by one. The results of scenario 6 are presented in Figure 17 with the following sequence of cases: 8, 63, 95, and 127. When the irradiance level was reduced by the transition of the cloud, the ABC-P\&O algorithm identified the new GMPPT power for the different cases without oscillations, whereas the GMPPT P\&O method had big oscillations around the GMPPT, and this is reflected in the current and voltage waveforms. Figure 18 illustrates that the proposed method provided the lowest error for the results seen in Figure 17. The ABC-P\&O algorithm presented a tracking factor of $98.62 \%$, whereas the GMPPT P\&O method only achieved $76.27 \%$. 


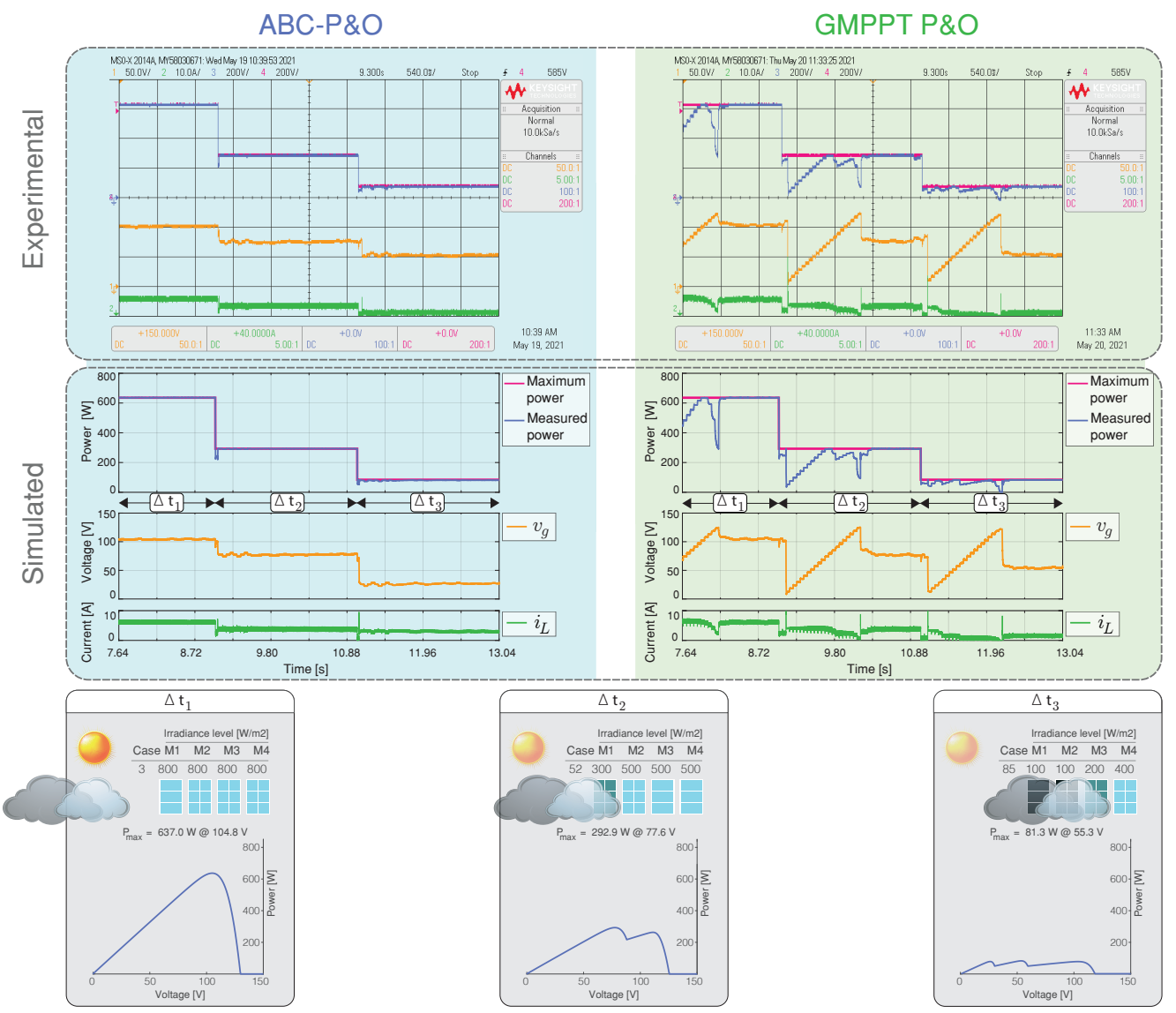

Figure 13. Simulated and experimental dynamic behavior of the MPPT algorithms for Scenario 4 with an output voltage $V_{o}=160 \mathrm{~V}$. The proposed MPPT algorithm (right) is compared with the GMPPT P\&O algorithm (right). CH1: $v_{g}(50 \mathrm{~V} / \mathrm{div}), \mathrm{CH} 2: i_{L}(10 \mathrm{~A} / \mathrm{div}), \mathrm{CH} 3$ : maximum power (200 W/div), CH4: measured power (200 W/div), and a time base of $540 \mathrm{~ms}$.

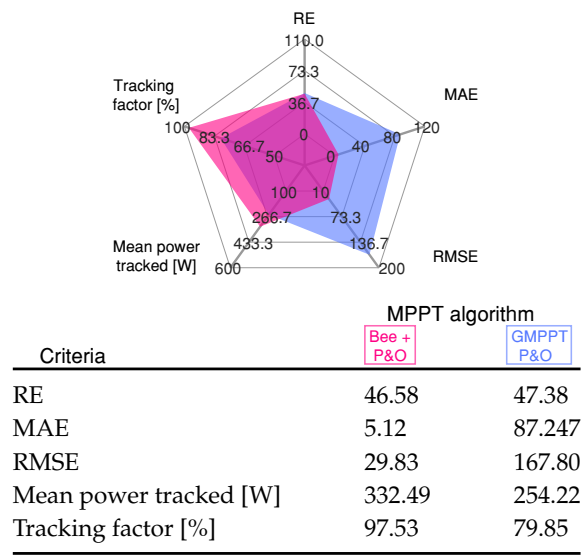

Figure 14. Comparative analysis of the MPPT methods for Scenario 4 shown in Figure 13.

\subsubsection{Scenario 7: Gradual Changes in Irradiance and Shading Pattern}

Finally, in this scenario, a high-resolution simulation of gradual changes in irradiance and shading pattern is presented, as shown in Figure 19. The eight selected cases $(1,2,39,40,72,73$, 105 , and 106) ensured gradual changes, which required long simulations. The proposed ABC-P\&O algorithm identified the new GMPP for each of the cases without oscillations, as shown in Figure 19. In this scenario, the ABC-P\&O algorithm presents resulted in a high tracking factor of $99.39 \%$, which validates the excellent performance of the algorithm in all the possible scenarios. 


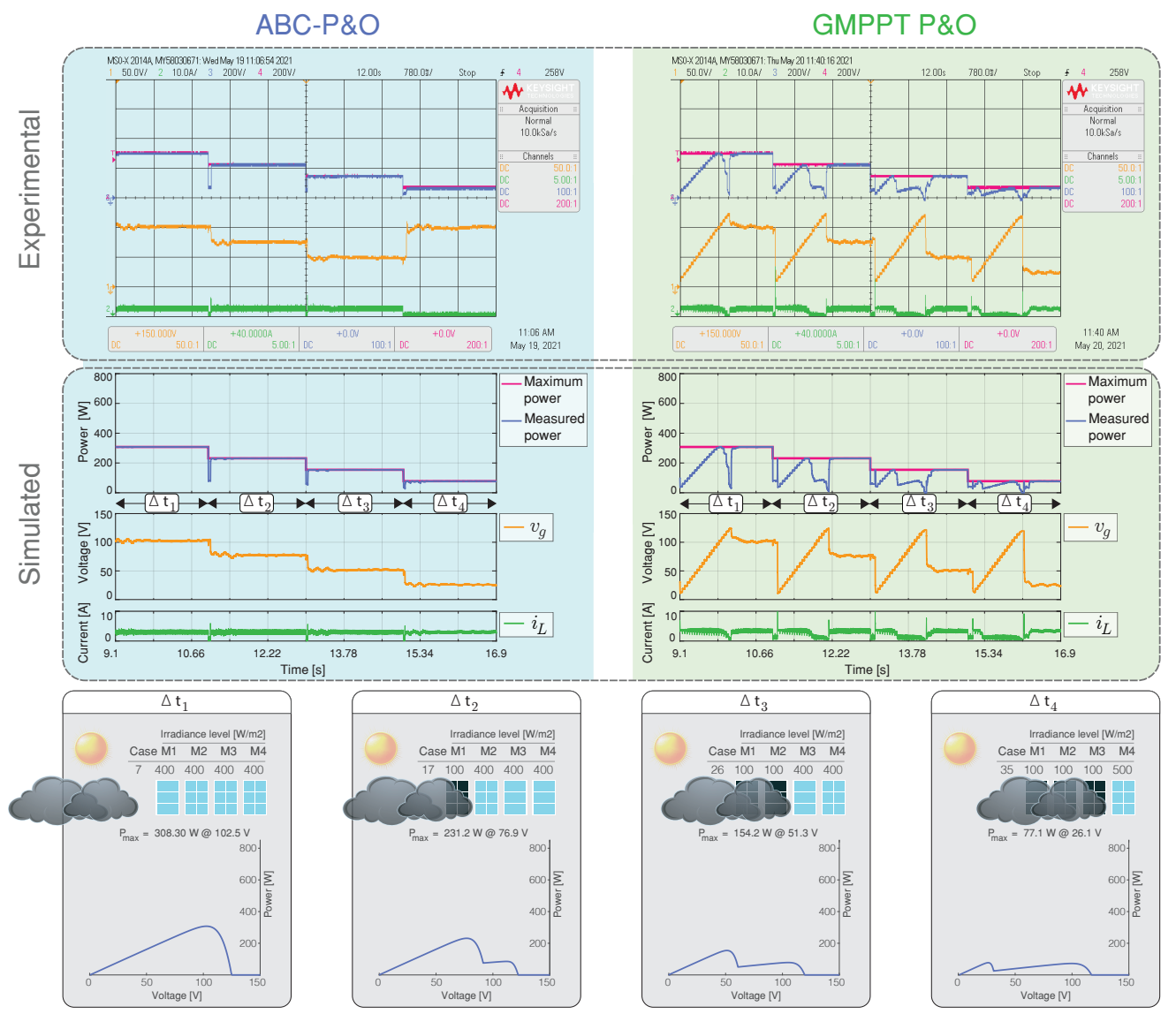

Figure 15. Simulated and experimental dynamic behavior of the MPPT algorithms for Scenario 5 with an output voltage $V_{o}=160 \mathrm{~V}$. The proposed MPPT algorithm (right) is compared with the GMPPT P\&O algorithm (right). CH1: $v_{g}(50 \mathrm{~V} / \mathrm{div}), \mathrm{CH} 2: i_{L}(10 \mathrm{~A} / \mathrm{div}), \mathrm{CH} 3$ : maximum power (200 W/div), CH4: measured power (200 W/div), and a time base of $780 \mathrm{~ms}$.

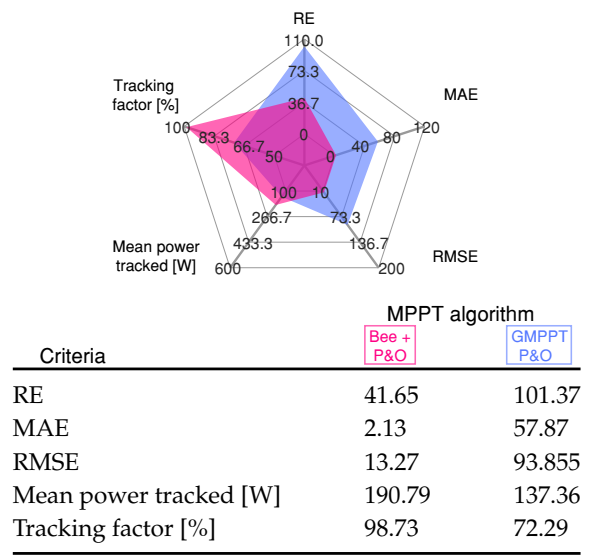

Figure 16. Comparative analysis of the MPPT methods under different nonuniform irradiance conditions for Scenario 5 shown in Figure 15. 


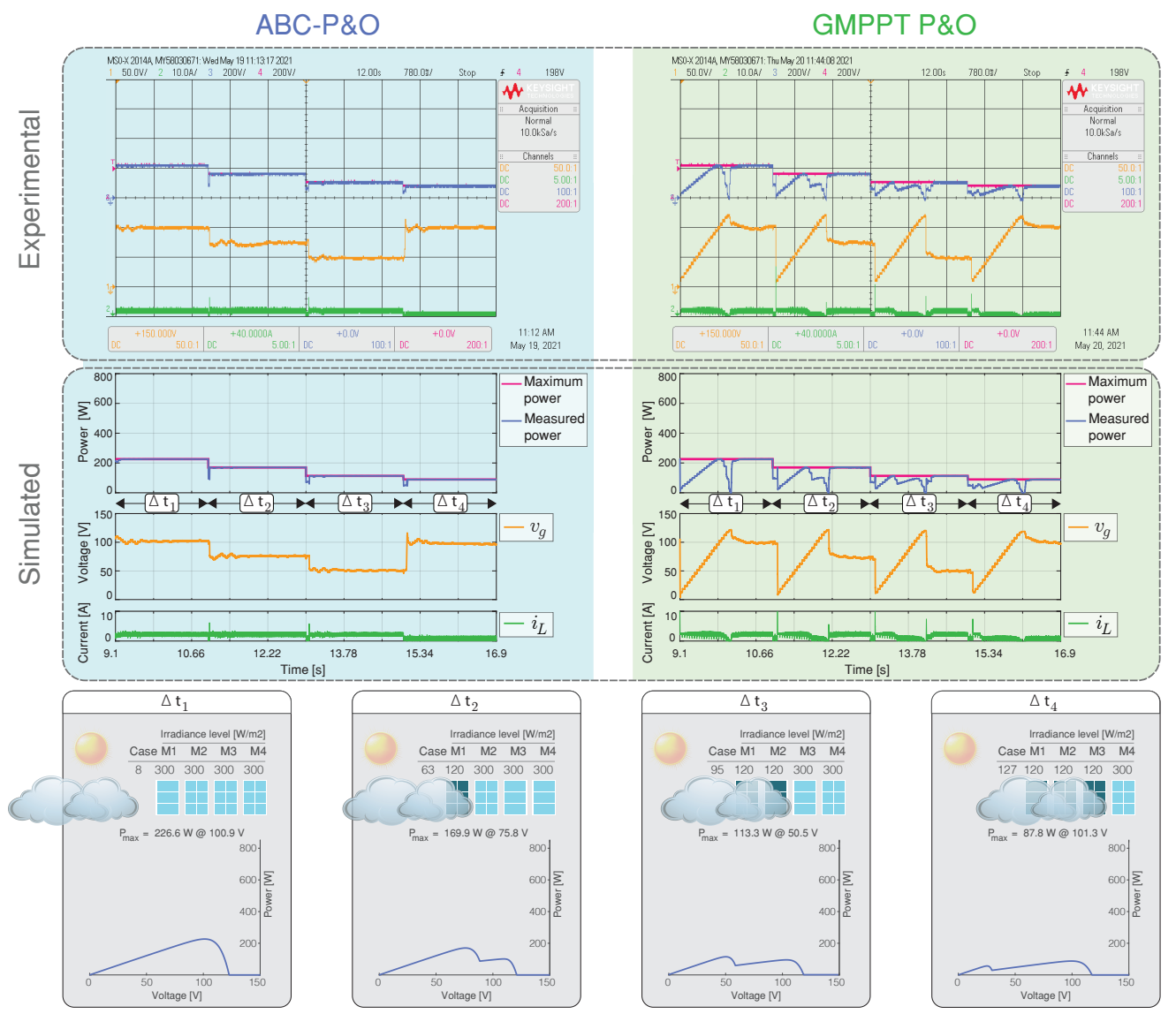

Figure 17. Simulated and experimental dynamic behavior of the MPPT algorithms for Scenario 6 with an output voltage $V_{o}=160 \mathrm{~V}$. The proposed MPPT algorithm (right) is compared with the GMPPT P\&O algorithm (right). CH1: $v_{g}(50 \mathrm{~V} / \mathrm{div}), \mathrm{CH} 2: i_{L}(10 \mathrm{~A} / \mathrm{div}), \mathrm{CH} 3$ : maximum power (200 W/div), CH4: measured power (200 W/div), and a time base of $780 \mathrm{~ms}$.

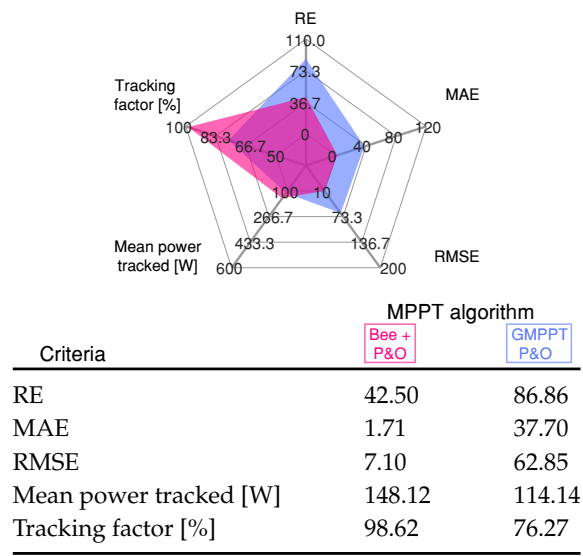

Figure 18. Comparative analysis of the MPPT methods for Scenario 6 shown in Figure 17. 


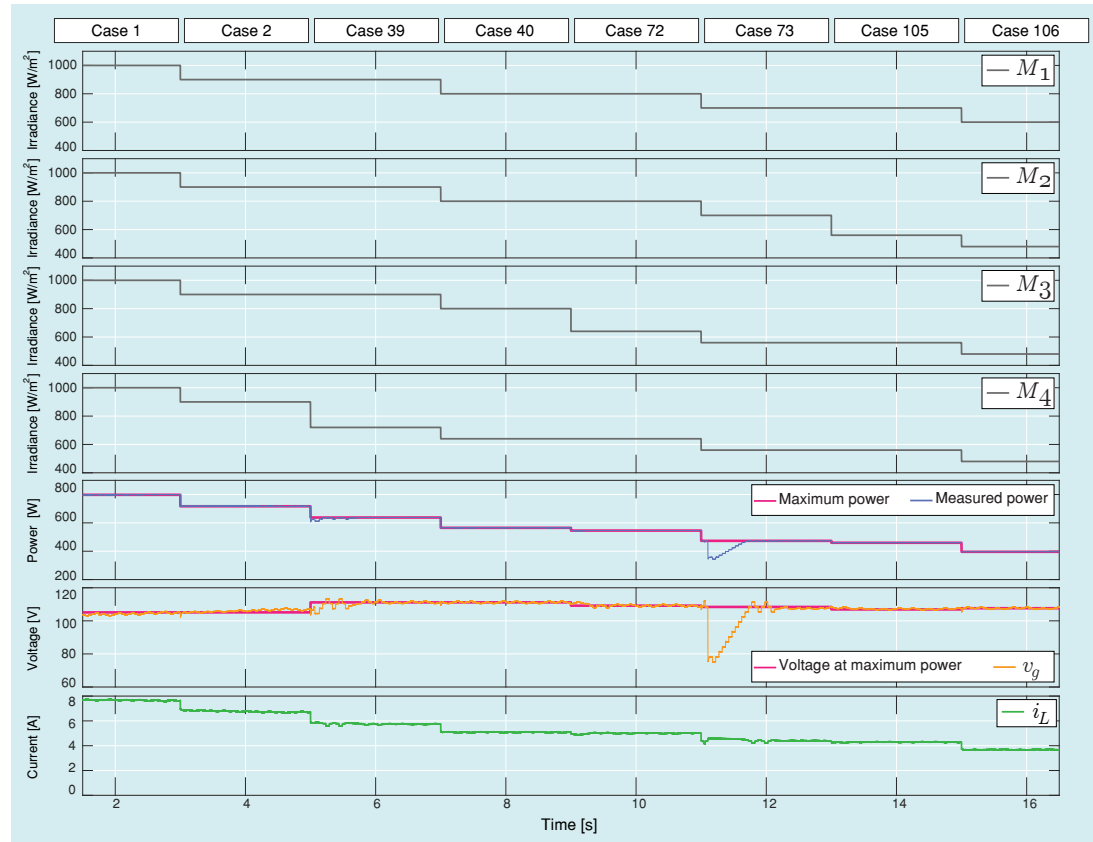

Figure 19. High-resolution simulation of the proposed ABC-P\&O MPPT algorithm for Scenario 7. The selected cases, presented in Figure 2, ensured gradual changes in irradiance and shading pattern at each of the four PV KC200GT modules $\left(M_{1}\right.$ to $\left.M_{4}\right)$ connected in series.

\section{Conclusions}

This paper presented a new hybrid MPPT method based on the ABC and P\&O algorithms to track the GMPP under uniform or PSCs. This novel strategy does not require additional measurements different from those needed by the $\mathrm{P} \& \mathrm{O}$ algorithm. The proposed method uses the conventional $\mathrm{P} \& \mathrm{O}$ algorithm to track the MPPT under uniform irradiance, and during irradiance variations, the ABC algorithm is employed.

Different challenge tests confirmed that the proposed method is robust and has fast-tracking ability with high MPP efficiency and without steady-state oscillations. The MPPT algorithm renders the optimal voltage the reference for the outer PI loop, and its quick response is due to the implementation of a double loop control with a fast inner current control.

An RT Box 1 was used to model the power circuit with the PLECS simulation tool and this way confirmed the effectiveness of the ABC-P\&O algorithm. The proposed MPPT algorithm and the double loop strategies were implemented in a low-cost commercial DSC, using C programming software. In this way, it was demonstrated that the proposed strategy has the advantage of a moderate computational cost, which allows it to be implemented in a low-cost DSC. Although the $\mathrm{ABC}$ strategy has a high computational cost, when included in a hybrid algorithm with $\mathrm{P} \& \mathrm{O}$ strategy, the computational cost decreases because the $\mathrm{ABC}$ is executed only when a solar irradiation changes occur. The ABC algorithm sometimes does not estimate an optimal reference voltage, but can achieve the GMPPT when P\&O operates. The ABC needs to have data available to estimate the optimal output reference voltage; nonetheless, it does not need a photovoltaic module model for its operation. The ABC-P\&O method gives excellent power tracking factor results compared to GMPPT P\&O for uniform or non-uniform irradiance conditions.

Future works will address an exhaustive comparison between the most relevant hybrid MPPT optimization techniques under uniform and nonuniform irradiance conditions operating in the same commercial low-cost microcontroller.

Author Contributions: Conceptualization, J.R., C.R., S.K., N.Y.-M. and C.G.-C.; methodology, J.R., C.R., N.Y.-M., S.K. and C.G.-C.; software, C.R. and C.G.-C.; validation, C.R. and C.G.-C.; formal analysis, J.R., S.K. and N.Y.-M.; investigation, J.R., C.R., S.K., N.Y.-M. and C.G.-C.; resources, J.R., C.R., S.K., N.Y.-M. and C.G.-C.; data curation, J.R., C.R. and C.G.-C.; writing-original draft preparation, J.R., C.R., and C.G.-C.; writing-review and editing, J.R., C.R., S.K., N.Y.-M. and C.G.-C.; visualization, J.R., C.R. and C.G.-C.; supervision, J.R., C.R. and S.K.; project administration, J.R., N.Y.-M. and C.R.; funding acquisition, J.R., C.R. and S.K. All authors have read and agreed to the published version of the manuscript. 
Funding: This research was funded by the Chilean Government under projects ANID/FONDECYT/ 1191680, ANID/FONDECYT/ 1210208, AC3E (ANID/BASAL/FB0008), ANID/PIA/ ACT192013, and SERC Chile (ANID/FONDAP/15110019).

Institutional Review Board Statement: Not applicable.

Informed Consent Statement: Not applicable.

Data Availability Statement: Not applicable.

Conflicts of Interest: The authors declare no conflict of interest. The funders had no role in the design of the study; in the collection, analyses, or interpretation of data; in the writing of the manuscript, or in the decision to publish the results.

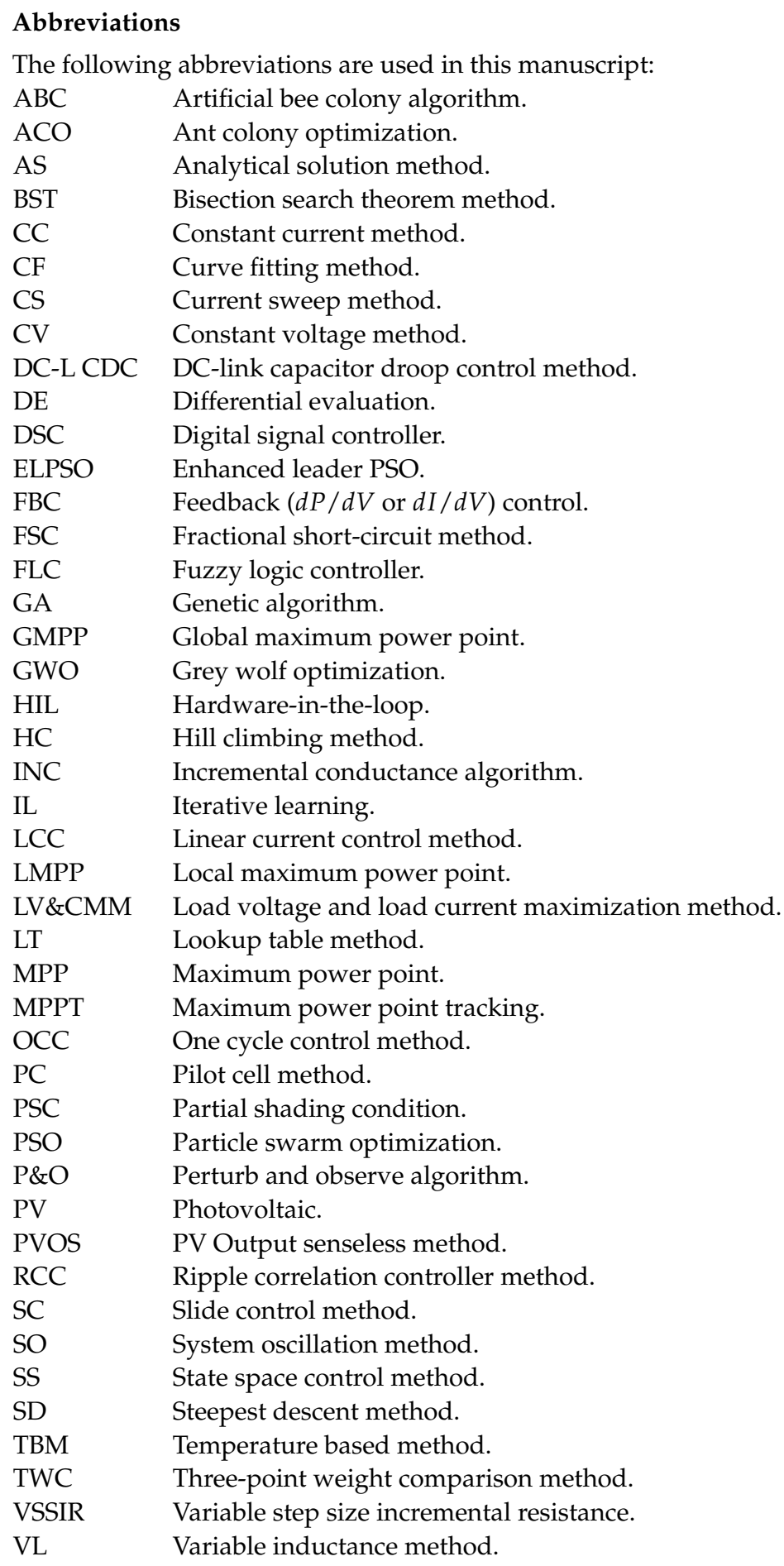




\section{References}

1. Bollipo, R.B.; Mikkili, S.; Bonthagorla, P.K. Hybrid, optimal, intelligent and classical PV MPPT techniques: A review. CSEE J. Power Energy Syst. 2021, 7, 9-33. [CrossRef]

2. Femia, N.; Petrone, G.; Spagnuolo, G.; Vitelli, M. Optimization of perturb and observe maximum power point tracking method. IEEE Trans. Power Electron. 2005, 20, 963-973. [CrossRef]

3. Ahmed, J.; Salam, Z. An improved perturb and observe (P\&O) maximum power point tracking (MPPT) algorithm for higher efficiency. Appl. Energy 2015, 150, 97-108. [CrossRef]

4. Kumar, N.; Hussain, I.; Singh, B.; Panigrahi, B.K. Framework of Maximum Power Extraction From Solar PV Panel Using Self Predictive Perturb and Observe Algorithm. IEEE Trans. Sustain. Energy 2018, 9, 895-903. [CrossRef]

5. Zakzouk, N.E.; Elsaharty, M.A.; Abdelsalam, A.K.; Helal, A.A.; Williams, B.W. Improved performance low-cost incremental conductance PV MPPT technique. IET Renew. Power Gener. 2016, 10, 561-574. [CrossRef]

6. Huynh, D.C.; Dunnigan, M.W. Development and Comparison of an Improved Incremental Conductance Algorithm for Tracking the MPP of a Solar PV Panel. IEEE Trans. Sustain. Energy 2016, 7, 1421-1429. [CrossRef]

7. Elgendy, M.A.; Atkinson, D.J.; Zahawi, B. Experimental investigation of the incremental conductance maximum power point tracking algorithm at high perturbation rates. IET Renew. Power Gener. 2016, 10, 133-139. [CrossRef]

8. Tan, C.Y.; Abd Rahim, N.; Selvaraj, J. Employing dual scaling mode for adaptive hill climbing method on buck converter. IET Renew. Power Gener. 2015, 9, 1010-1018. [CrossRef]

9. Ons, Z.; Aymen, J.; Craciunescu, A.; Popescu, M. Comparison of Hill-Climbing and Artificial Neural Network Maximum Power Point Tracking Techniques for Photovoltaic Modules. In Proceedings of the 2015 Second International Conference on Mathematics and Computers in Sciences and in Industry (MCSI), Sliema, Malta, 17 August 2015; pp. 19-23. [CrossRef]

10. Jain, S.; Agarwal, V. A new algorithm for rapid tracking of approximate maximum power point in photovoltaic systems. IEEE Power Electron. Lett. 2004, 2, 16-19. [CrossRef]

11. Pradeep, K.P.J.; Chandra Mouli, C.; Sai Prasad Reddy, K.; Nagabhushan Raju, K. Design and Implementation of Maximum Power Point Tracking in Photovoltaic Systems. Int. J. Eng. Sci. Invent. 2015, 4, 37-43.

12. Tsang, K.; Chan, W. Maximum power point tracking for PV systems under partial shading conditions using current sweeping. Energy Convers. Manag. 2015, 93, 249-258. [CrossRef]

13. Sreeraj, E.; Chatterjee, K.; Bandyopadhyay, S. One-Cycle-Controlled Single-Stage Single-Phase Voltage-Sensorless Grid-Connected PV System. IEEE Trans. Ind. Electron. 2013, 60, 1216-1224. [CrossRef]

14. Fortunato, M.; Giustiniani, A.; Petrone, G.; Spagnuolo, G.; Vitelli, M. Maximum Power Point Tracking in a One-Cycle-Controlled Single-Stage Photovoltaic Inverter. IEEE Trans. Ind. Electron. 2008, 55, 2684-2693. [CrossRef]

15. Galtieri, J.; Krein, P.T. Ripple Correlation Control with Capacitive Compensation for Photovoltaic Applications. In Proceedings of the 2018 IEEE 19th Workshop on Control and Modeling for Power Electronics (COMPEL), Padua, Italy, 25-28 June 2018; pp. 1-7. [CrossRef]

16. Boonmee, C.; Kumsuwan, Y. Modified maximum power point tracking based-on ripple correlation control application for single-phase VSI grid-connected PV systems. In Proceedings of the 2013 10th International Conference on Electrical Engineering/Electronics, Computer, Telecommunications and Information Technology, Krabi, Thailand, 15-17 May 2013; pp. 1-6. [CrossRef]

17. Yilmaz, U.; Kircay, A.; Borekci, S. PV system fuzzy logic MPPT method and PI control as a charge controller. Renew. Sustain. Energy Rev. 2018, 81, 994-1001. [CrossRef]

18. Obaid, Z. A.; Cipcigan, L. M.; Muhssin, M. T. Power system oscillations and control: Classifications and PSSs' design methods: A review. Renew. Sustain. Energy Rev. 2017, 79, 839-849. [CrossRef]

19. Levron, Y.; Shmilovitz, D. Maximum Power Point Tracking Employing Sliding Mode Control. IEEE Trans. Circuits Syst. I Regul. Pap. 2013, 60, 724-732. [CrossRef]

20. Zhang, F.; Maddy, J.; Premier, G.; Guwy, A. Novel current sensing photovoltaic maximum power point tracking based on sliding mode control strategy. Sol. Energy 2015, 118, 80-86. [CrossRef]

21. Jamil, M.; Saeed, H.; Qaisar, S.; Felemban, E.A. Maximum power point tracking of a solar system using state space averaging for wireless sensor network. In Proceedings of the 2013 IEEE International Conference on Smart Instrumentation, Measurement and Applications (ICSIMA), Kuala Lumpur, Malaysia, 25-27 November 2013; pp. 1-6. [CrossRef]

22. Raedani, R.; Hanif, M. Design, testing and comparison of P O, IC and VSSIR MPPT techniques. In Proceedings of the 2014 International Conference on Renewable Energy Research and Application (ICRERA), Milwaukee, WI, USA, 19-22 October 2014; pp. 322-330. [CrossRef]

23. Ahmed, E.M.; Shoyama, M. Stability study of variable step size incremental conductance/impedance MPPT for PV systems. In Proceedings of the 8th International Conference on Power Electronics-ECCE Asia, Jeju, Korea, 30 May-3 June 2011; pp. 386-392. [CrossRef]

24. Mumtaz, S.; Ahmad, S.; Khan, L.; Ali, S.; Kamal, T.; Hassan, S.Z. Adaptive Feedback Linearization Based NeuroFuzzy Maximum Power Point Tracking for a Photovoltaic System. Energies 2018, 11, 606. [CrossRef]

25. Zhang, L.; Hurley, W.G.; Wölfle, W.H. A New Approach to Achieve Maximum Power Point Tracking for PV System With a Variable Inductor. IEEE Trans. Power Electron. 2011, 26, 1031-1037. [CrossRef] 
26. Khatib, T.; Elmenreich, W.; Mohamed, A. Simplified I-V Characteristic Tester for Photovoltaic Modules Using a DC-DC Boost Converter. Sustainability 2017, 9, 657. [CrossRef]

27. Abdel-Salam, M.; El-Mohandes, M.T.; Goda, M. An improved perturb-and-observe based MPPT method for PV systems under varying irradiation levels. Sol. Energy 2018, 171, 547-561. [CrossRef]

28. Hsiao, Y.T.; Chen, C.H. Maximum power tracking for photovoltaic power system. In Proceedings of the Conference Record of the 2002 IEEE Industry Applications Conference. 37th IAS Annual Meeting (Cat. No.02CH37344), Pittsburgh, PA, USA, 13-18 October 2002; Volume 2, pp. 1035-1040. [CrossRef]

29. Li, G.; Jin, Y.; Akram, M.; Chen, X.; Ji, J. Application of bio-inspired algorithms in maximum power point tracking for PV systems under partial shading conditions-A review. Renew. Sustain. Energy Rev. 2018, 81, 840-873. [CrossRef]

30. Batarseh, M.G.; Za'ter, M.E. Hybrid maximum power point tracking techniques: A comparative survey, suggested classification and uninvestigated combinations. Sol. Energy 2018, 169, 535-555. [CrossRef]

31. Xiao, W.; Dunford, W.G.; Palmer, P.R.; Capel, A. Application of Centered Differentiation and Steepest Descent to Maximum Power Point Tracking. IEEE Trans. Ind. Electron. 2007, 54, 2539-2549. [CrossRef]

32. Pradhan, R.; Subudhi, B. A steepest-descent based maximum power point tracking technique for a photovoltaic power system. In Proceedings of the 2012 2nd International Conference on Power, Control and Embedded Systems, Allahabad, India, 17-19 December 2012; pp. 1-6. [CrossRef]

33. Rodriguez, C.; Amaratunga, G.A.J. Analytic Solution to the Photovoltaic Maximum Power Point Problem. IEEE Trans. Circuits Syst. I: Regul. Pap. 2007, 54, 2054-2060. [CrossRef]

34. Kuperman, A. Comments on "An Analytical Solution for Tracking Photovoltaic Module MPP". IEEE J. Photovoltaics 2014, 4, 734-735. [CrossRef]

35. Farivar, G.; Asaei, B.; Mehrnami, S. An Analytical Solution for Tracking Photovoltaic Module MPP. IEEE J. Photovoltaics 2013, 3, 1053-1061. [CrossRef]

36. Coelho, R.F.; Concer, F.M.; Martins, D.C. A MPPT approach based on temperature measurements applied in PV systems. In Proceedings of the 2010 IEEE International Conference on Sustainable Energy Technologies (ICSET), Kandy, Sri Lanka, 6-9 December 2010; pp. 1-6. [CrossRef]

37. Correa-Betanzo, C.; Calleja, H.; De León-Aldaco, S. Module temperature models assessment of photovoltaic seasonal energy yield. Sustain. Energy Technol. Assessments 2018, 27, 9-16. [CrossRef]

38. Wang, P.; Zhu, H.; Shen, W.; Choo, F.H.; Loh, P.C.; Tan, K.K. A novel approach of maximizing energy harvesting in photovoltaic systems based on bisection search theorem. In Proceedings of the 2010 Twenty-Fifth Annual IEEE Applied Power Electronics Conference and Exposition (APEC), Palm Springs, CA, USA, 21-25 February 2010; pp. 2143-2148. [CrossRef]

39. Chun, S.; Kwasinski, A. Analysis of Classical Root-Finding Methods Applied to Digital Maximum Power Point Tracking for Sustainable Photovoltaic Energy Generation. IEEE Trans. Power Electron. 2011, 26, 3730-3743. [CrossRef]

40. Qing, X.; Sun, H.; Feng, X.; Chung, C.Y. Submodule-Based Modeling and Simulation of a Series-Parallel Photovoltaic Array Under Mismatch Conditions. IEEE J. Photovoltaics 2017, 7, 1731-1739. [CrossRef]

41. Tauseef, M.; Nowicki, E. A simple and cost effective maximum power point tracker for PV arrays employing a novel constant voltage technique. In Proceedings of the 2012 25th IEEE Canadian Conference on Electrical and Computer Engineering (CCECE), Montreal, QC, Canada, 29 April-2 May 2012; pp. 1-4. [CrossRef]

42. Leedy, A.W.; Guo, L.; Aganah, K.A. A constant voltage MPPT method for a solar powered boost converter with DC motor load. In Proceedings of the 2012 Proceedings of IEEE Southeastcon, Orlando, FL, USA, 15-18 March 2012; pp. 1-6. [CrossRef]

43. Huang, Y.P.; Hsu, S.Y. A performance evaluation model of a high concentration photovoltaic module with a fractional open circuit voltage-based maximum power point tracking algorithm. Comput. Electr. Eng. 2016, 51, 331-342. [CrossRef]

44. Di, X.; Yundong, M.; Qianhong, C. A global maximum power point tracking method based on interval short-circuit current. In Proceedings of the 2014 16th European Conference on Power Electronics and Applications, Lappeenranta, Finland, 26-28 August 2014; pp. 1-8. [CrossRef]

45. Leedy, A.W.; Garcia, K.E. Approximation of P-V characteristic curves for use in maximum power point tracking algorithms. In Proceedings of the 45th Southeastern Symposium on System Theory, Waco, TX, USA, 11 March 2013; pp. 88-93. [CrossRef]

46. Salas, V.; Olías, E.; Barrado, A.; Lázaro, A. Review of the maximum power point tracking algorithms for stand-alone photovoltaic systems. Sol. Energy Mater. Sol. Cells 2006, 90, 1555-1578. [CrossRef]

47. Hassouni, B.E.; Ourahou, M.; Ayrir, W.; Haddi, A.; Amrani, A. A Study of Efficient MPPT Techniques for Photovoltaic System Using Boost Converter. Int. J. Emerg. Electr. Power Syst. 2018, 19, 20170180.:10.1515/ijeeps-2017-0180. [CrossRef]

48. Desai, H.P.; Patel, H.K. Maximum Power Point Algorithm in PV Generation: An Overview. In Proceedings of the 2007 7th International Conference on Power Electronics and Drive Systems, Bangkok, Thailand, 11 April 2007; pp. 624-630. [CrossRef]

49. Shmilovitz, D. On the control of photovoltaic maximum power point tracker via output parameters. IEE Proc.-Electr. Power Appl. 2005, 152, 239-248. [CrossRef]

50. Shabaan, S.; Abu El-Sebah, M.I.; Bekhit, P. Maximum power point tracking for photovoltaic solar pump based on ANFIS tuning system. J. Electr. Syst. Inf. Technol. 2018, 5, 11-22. [CrossRef]

51. Lee, S.J.; Park, H.Y.; Kim, G.H.; Seo, H.R.; Ali, M.H.; Park, M.; Yu, I.K. The experimental analysis of the grid- connected PV system applied by POS MPPT. In Proceedings of the 2007 International Conference on Electrical Machines and Systems (ICEMS), Seoul, Korea, 8-11 October 2007; pp. 1786-1791. 
52. Sundareswaran, K.; Vigneshkumar, V.; Palani, S. Development of a hybrid genetic algorithm/perturb and observe algorithm for maximum power point tracking in photovoltaic systems under non-uniform insolation. IET Renew. Power Gener. 2015, 9, 757-765. [CrossRef]

53. Manickam, C.; Raman, G.R.; Raman, G.P.; Ganesan, S.I.; Nagamani, C. A Hybrid Algorithm for Tracking of GMPP Based on P\&O and PSO With Reduced Power Oscillation in String Inverters. IEEE Trans. Ind. Electron. 2016, 63, 6097-6106. [CrossRef]

54. Lian, K.L.; Jhang, J.H.; Tian, I.S. A Maximum Power Point Tracking Method Based on Perturb-and-Observe Combined With Particle Swarm Optimization. IEEE J. Photovoltaics 2014, 4, 626-633. [CrossRef]

55. Abdulkadir, M.; Yatim, A.H.M. Hybrid maximum power point tracking technique based on PSO and incremental conductance. In Proceedings of the 2014 IEEE Conference on Energy Conversion (CENCON), Johor Bahru, Malaysia, 13-14 October 2014; pp. 271-276. [CrossRef]

56. Eltamaly, A.M.; Farh, H.M. Dynamic global maximum power point tracking of the PV systems under variant partial shading using hybrid GWO-FLC. Sol. Energy 2019, 177, 306-316. [CrossRef]

57. Pilakkat, D.; Kanthalakshmi, S. An improved P\&O algorithm integrated with artificial bee colony for photovoltaic systems under partial shading conditions. Sol. Energy 2019, 178, 37-47. [CrossRef]

58. Alajmi, B.N.; Ahmed, K.H.; Finney, S.J.; Williams, B.W. Fuzzy-Logic-Control Approach of a Modified Hill-Climbing Method for Maximum Power Point in Microgrid Standalone Photovoltaic System. IEEE Trans. Power Electron. 2011, 26, 1022-1030. [CrossRef]

59. Sher, H.A.; Murtaza, A.F.; Noman, A.; Addoweesh, K.E.; Al-Haddad, K.; Chiaberge, M. A New Sensorless Hybrid MPPT Algorithm Based on Fractional Short-Circuit Current Measurement and P O MPPT. IEEE Trans. Sustain. Energy 2015, 6, 1426-1434. [CrossRef]

60. Ram, J.P.; Pillai, D.S.; Rajasekar, N.; Strachan, S.M. Detection and Identification of Global Maximum Power Point Operation in Solar PV Applications Using a Hybrid ELPSO-P O Tracking Technique. IEEE J. Emerg. Sel. Top. Power Electron. 2020, 8, 1361-1374. [CrossRef]

61. Joisher, M.; Singh, D.; Taheri, S.; Espinoza-Trejo, D.R.; Pouresmaeil, E.; Taheri, H. A Hybrid Evolutionary-Based MPPT for Photovoltaic Systems Under Partial Shading Conditions. IEEE Access 2020, 8, 38481-38492. [CrossRef]

62. Mohanty, S.; Subudhi, B.; Ray, P.K. A Grey Wolf-Assisted Perturb Observe MPPT Algorithm for a PV System. IEEE Trans. Energy Convers. 2017, 32, 340-347. [CrossRef]

63. Ali, A.; Almutairi, K.; Padmanaban, S.; Tirth, V.; Algarni, S.; Irshad, K.; Islam, S.; Zahir, M.H.; Shafiullah, M.; Malik, M.Z Investigation of MPPT Techniques Under Uniform and Non-Uniform Solar Irradiation Condition-A Retrospection. IEEE Access 2020, 8, 127368-127392. [CrossRef]

64. Yap, K.Y.; Sarimuthu, C.R.; Lim, J.M.Y. Artificial Intelligence Based MPPT Techniques for Solar Power System: A review. J. Mod. Power Syst. Clean Energy 2020, 8, 1043-1059. [CrossRef]

65. Li, X.; Wen, H.; Hu, Y.; Du, Y.; Yang, Y. A Comparative Study on Photovoltaic MPPT Algorithms Under EN50530 Dynamic Test Procedure. IEEE Trans. Power Electron. 2021, 36, 4153-4168. [CrossRef]

66. Li, X.; Wang, Q.; Wen, H.; Xiao, W. Comprehensive Studies on Operational Principles for Maximum Power Point Tracking in Photovoltaic Systems. IEEE Access 2019, 7, 121407-121420. [CrossRef]

67. Díaz Martínez, D.; Trujillo Codorniu, R.; Giral, R.; Vázquez Seisdedos, L. Evaluation of particle swarm optimization techniques applied to maximum power point tracking in photovoltaic systems. Int. J. Circuit Theory Appl. 2021, 49, 1849-1867. [CrossRef]

68. Hanzaei, S.H.; Gorji, S.A.; Ektesabi, M. A Scheme-Based Review of MPPT Techniques With Respect to Input Variables Including Solar Irradiance and PV Arrays' Temperature. IEEE Access 2020, 8, 182229-182239. [CrossRef]

69. Liu, F.; Kang, Y.; Zhang, Y.; Duan, S. Comparison of P O and hill climbing MPPT methods for grid-connected PV converter. In Proceedings of the 2008 3rd IEEE Conference on Industrial Electronics and Applications, Singapore, 3-5 June 2008 ; pp. 804-807. [CrossRef]

70. Ghasemi, M.A.; Foroushani, H.M.; Parniani, M. Partial Shading Detection and Smooth Maximum Power Point Tracking of PV Arrays Under PSC. IEEE Trans. Power Electron. 2016, 31, 6281-6292. [CrossRef]

71. El Aroudi, A.; Martínez-Treviño, B.A.; Vidal-Idiarte, E.; Cid-Pastor, A. Fixed switching frequency digital sliding-mode control of DC-DC power supplies loaded by constant power loads with inrush current limitation capability. Energies 2019, $12,1055$. [CrossRef]

72. Vidal-Idiarte, E.; Marcos-Pastor, A.; Garcia, G.; Cid-Pastor, A.; Martinez-Salamero, L. Discrete-time sliding-mode-based digital pulse width modulation control of a boost converter. IET Power Electron. 2015, 8, 708-714. [CrossRef]

73. Vidal-Idiarte, E.; Marcos-Pastor, A.; Giral, R.; Calvente, J.; Martinez-Salamero, L. Direct digital design of a sliding mode-based control of a PWM synchronous buck converter. IET Power Electron. 2017, 10, 1714-1720. [CrossRef]

74. Restrepo, C.; González-Castaño, C.; Muñoz, J.; Chub, A.; Vidal-Idiarte, E.; Giral, R. An MPPT algorithm for PV systems based on a simplified photo-diode model. IEEE Access 2021, 9, 33189-33320. [CrossRef]

75. Kamran, M.; Mudassar, M.; Fazal, M.R.; Asghar, M.U.; Bilal, M.; Asghar, R. Implementation of improved Perturb \& Observe MPPT technique with confined search space for standalone photovoltaic system. J. King Saud-Univ.-Eng. Sci. 2018, 32, $432-441$.

76. Tereshko, V. Reaction-diffusion model of a honeybee colony's foraging behaviour. In International Conference on Parallel Problem Solving from Nature; Springer: Berlin/Heidelberg, Germany, 2000; pp. 807-816.

77. Tereshko, V.; Loengarov, A. Collective decision making in honey-bee foraging dynamics. Comput. Inf. Syst. $2005,9,1$. 
78. González-Castaño, C.; Restrepo, C.; Kouro, S.; Rodriguez, J. MPPT Algorithm Based on Artificial Bee Colony for PV System. IEEE Access 2021, 9, 43121-43133. [CrossRef]

79. Nozohour-leilabady, B.; Fazelabdolabadi, B. On the application of artificial bee colony (ABC) algorithm for optimization of well placements in fractured reservoirs; efficiency comparison with the particle swarm optimization (PSO) methodology. Petroleum 2016, 2, 79-89. [CrossRef]

80. Soufyane Benyoucef, A.; Chouder, A.; Kara, K.; Silvestre, S. Artificial bee colony based algorithm for maximum power point tracking (MPPT) for PV systems operating under partial shaded conditions. Appl. Soft Comput. 2015, 32, 38-48. [CrossRef] 